\title{
Two wind-driven modes of winter sea ice variability in the Barents Sea
}

\author{
Christophe Herbaut*, Marie-Noëlle Houssais, Sally Close, Anne-Cécile Blaizot \\ Sorbonne Universités (UPMC Université Paris 06)-CNRS-IRD-MNHN, LOCEAN Laboratory, 4 place Jussieu, F-75005 Paris, France
}

\section{A R T I C L E I N F O}

\section{Article history:}

Received 27 March 2015

Received in revised form

5 October 2015

Accepted 12 October 2015

\section{Keywords:}

Sea ice

Barents Sea

Atlantic Water

Interannual variability

\begin{abstract}
A B S T R A C T
The interannual variability of the winter sea ice area in the Barents Sea is investigated using SMMR-SSM/I data and a coupled ocean-sea ice model over the period 1979-2012. Our analysis reveals that the sea ice area in the northern and eastern parts of the Barents Sea do not covary. This contrast in behavior allows us to associate two distinct modes of variability with these two regions, with the variability of the overall Barents Sea ice cover being predominantly captured by the northern mode. Both modes show a dominant, near in-phase response to the surface wind, both being associated with different spatial patterns. The northern mode emerges in response to northwesterly wind anomalies which favor the export of ice and surface polar water from the Arctic between Svalbard and Franz Josef Land. Atlantic Water temperature anomalies, formed concomitantly with northerly wind anomalies in the vicinity of the Barents Sea Opening, also influence the northern mode in the following winter. These temperature anomalies are linked to local convergence of the oceanic heat transport. The delayed influence of the ocean on the sea ice is found primarily in the northeastern Barents Sea and occurs through the re-emergence of the Atlantic water temperature anomalies at the surface in the following fall and winter. An ocean-to-atmosphere feedback initiated by October SST anomalies in the central Barents Sea is further identified. This feedback is hypothesized to enhance the sea ice response in the northern Barents Sea by promoting the formation of meridional wind anomalies. In contrast, the eastern mode of variability of the Barents Sea ice mainly responds to wind anomalies with a strong zonal component, and is less influenced by the Atlantic Water temperature variability than the northern mode. While our results clearly highlight a role of the ocean in the Barents Sea ice variability, this role appears to be more spatially restricted following the sudden northward retreat of the ice margin in 2004. In particular, the sudden drop in the sea ice area in 2004 could not be linked to earlier Atlantic water changes in the Barents Sea Opening.
\end{abstract}

(c) 2015 Elsevier Ltd. All rights reserved.

\section{Introduction}

The summer Arctic sea ice cover has exhibited significant decline over recent decades, marked by the extreme events of September 2007 and 2012 (e.g Stroeve et al., 2012; Zhang et al., 2013). This retreat has been hypothesized to drive changes in the winter atmospheric circulation, especially by favoring the emergence of specific phases of the North Atlantic Oscillation (NAO) (e.g., Deser et al., 2007; Francis et al., 2009; Strong et al., 2009; Jaiser et al., 2012). In winter, the negative trend in the sea ice extent is smaller and more recent (Comiso, 2006); nevertheless changes in winter sea ice concentration have been shown to exert some influence on the atmospheric conditions (Alexander et al., 2004, Strong et al., 2009). The ice cover of the Barents Sea is, however, an exception to the seasonality in ice loss trends noted above. With the largest winter decrease among all the Arctic seas, the Barents Sea ice cover shows almost as strong a negative trend in winter as in the

\footnotetext{
${ }^{*}$ Corresponding author.
}

other seasons (Kern et al., 2010; Cavalieri and Parkinson, 2012). This remarkable retreat is thought to have favored cold winter conditions (Petoukhov and Semenov, 2010) or cold extremes (Gerber et al., 2014) over Europe, a link which may be enhanced in the future (Yang and Christensen, 2012). Winter sea ice concentration (SIC) anomalies in the Barents Sea also have the potential to generate large scale SLP anomalies (Liptak and Strong, 2014), with possible implications for coupled atmosphere-sea ice interactions (Yang and Yuan, 2014)

The first mode of variability of the Northern Hemisphere winter sea ice concentration is characterized by two dipoles in the marginal ice zones of the Atlantic and Pacific sectors (Deser et al., 2000; Ukita et al., 2007), which, at least in the last decades of the 20th century, was partly driven by the NAO (Deser et al., 2000; Rigor et al., 2002). Superimposed upon this large-scale pattern of variability, regional contrasts exist between the different Arctic seas. In particular, in the Barents Sea (see Fig. 1 for the geography of the region), the interannual variability of the winter sea ice extent can be related to a simultaneous pattern of SLP anomalies centered over the Greenland-Barents Seas (Sorteberg and 


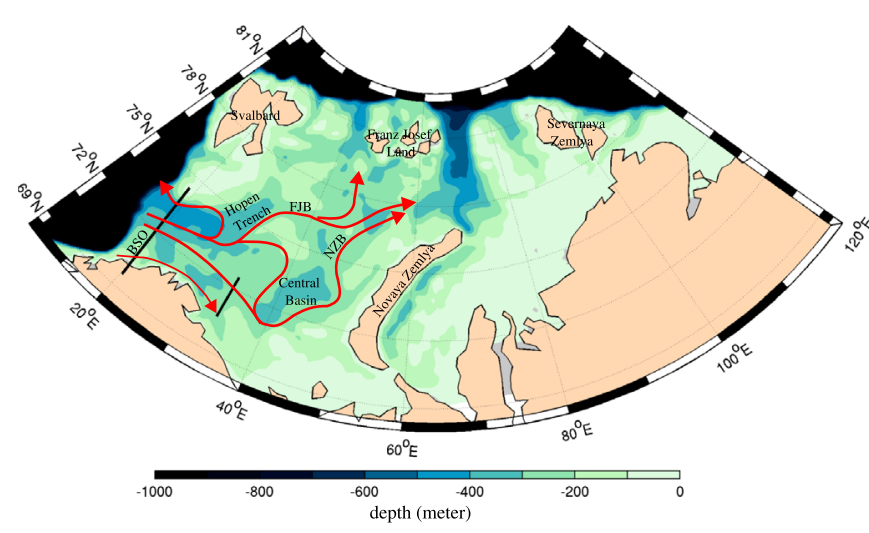

Fig. 1. Schematic of the circulation of Atlantic Water, showing the Novaya Zemlya Branch (NZB) and the Franz Josef Branch (FJB), and the bathymetry (in meters) in the Barents Sea. The black lines define the Barents Sea Opening (BSO) section (western line) and the Kola section (eastern line).

Kvingedal, 2006). In April, at the time of its maximum, the sea ice extent was found to be linked to an SLP dipole having one center of action over the Norwegian Sea and another over western Siberia (Pavlova et al., 2014). In both cases, these SLP anomalies generated northerly wind anomalies. While such anomalies were assumed to enhance the ice transport from the Arctic into the northern Barents Sea and favor ice production through cold air advection, their actual impact was not evaluated. However, several studies have highlighted the lagged effect of the surface wind on the interannual variability of the sea ice cover in the Barents Sea. According to Årthun et al. (2012) and Schlichtholz (2011), the highest correlation between the sea ice area and the surface wind occurs when the wind leads the sea ice by about a year. The lag suggests some implication of the ocean circulation and the associated heat transport in this relationship, and, in further support of this notion, at interannual to decadal time scales, Sorteberg and Kvingedal (2006) suggest that the storm activity in the western Nordic Seas could force a delayed response of the Barents Sea ice edge by driving changes in the Atlantic Water (AW) inflow through the Barents Sea opening (BSO). In all cases, however, the exact mechanisms and time scales involved in the response of the sea ice to the wind are not explicitly detailed.

The most natural link between the ocean and the sea ice in the Barents Sea is to be found in the AW flow entering the Barents Sea from the west and carrying along a large heat reservoir. While this AW loses most of its heat to the atmosphere upon crossing the Barents Sea, some of this heat is brought eastward and northward to the ice edge and can potentially affect sea ice through melting. Indeed, using a sea ice-ocean simulation, Årthun et al. (2012) found a robust anticorrelation $(-0.63)$ between the annual mean heat transport at BSO and the Barents Sea ice cover when the transport led by 1 year. A similar result was found by Sandø et al. (2014) in a coupled model in which a reduction in sea ice growth was accompanied by increased heat transport to the western Barents Sea. These variations in heat transport, which are mainly due to changes in volume transport (Skagseth et al., 2008; Årthun et al., 2012), were hypothesized to drive the variability of the heat content in the southern Barents Sea; in contrast the ocean-atmosphere heat flux has been suggested to contribute only a small fraction to the heat content changes (Smedsrud et al., 2010). The link between the AW temperature and the sea ice cover in the Barents Sea was initially suggested, albeit qualitatively, by Loeng (1991). More recently, a seasonal analysis by Schlichtholz (2011) highlighted the prominent role of the Atlantic Water heat content in the BSO region on the Barents Sea ice cover, suggesting that the most influential changes in the AW occur in early summer, with these anomalies being able to explain $75 \%$ of the variance of the sea ice variability in the following winter. In contrast to Årthun et al., (2012), Nakamura et al. (2014) suggested that the temperature anomalies could be advected from the Atlantic Ocean by the mean circulation. It remains, however, unclear what processes actually drive the AW heat content in the Barents Sea and control the time lag of the sea ice response in different regions of the Barents Sea.

The aim of this study is to better understand the variability of the winter sea ice concentration in the Barents Sea and its links to the ocean and the atmosphere at the interannual time scale. We show that the variability in the northern Barents Sea can be distinguished from that in the southeastern Barents Sea. For each of the two modes, we first analyze the influence of the atmospheric forcing. In particular, we try to estimate the relative importance of the in-phase and lagged sea ice responses, as well as the relative contributions of the sea ice convergence and growth to these responses. In a second step, we analyze the impact of the ocean on the Barents Sea ice cover variability. To clarify the link with the heat transport through BSO, the influence of both the inflow and outflow branches of the transport is considered, as well as their link to the evolution of the sea ice and heat content in the interior Barents Sea. The paper is organized as follows: the observations and the model simulation are introduced in Section 2. In Section 3, the performance of the model in the Barents Sea is briefly evaluated. Results are presented in Section 4 and discussed in Section 5. Some conclusions are provided in Section 6

\section{Data and methods}

\subsection{Observations}

Monthly SIC estimated from passive microwave radiometer (SSM/I and SMMR) observations, gridded on a $25 \times 25 \mathrm{~km}$ grid (National Snow and Ice Data Center; Comiso, 2000), are analyzed over the period 1979-2012. Surface atmosphere temperatures (SAT) and winds extracted from the ERA-I reanalysis (Dee et al., 2011) are used to characterize the atmospheric variability. The hydrographic conditions at the BSO are characterized using CTD data from the Oceanographic Database of the International Council for Exploration of the Sea (http://www.ices.dk). A time series of seasonal (winter is attributed to the JFM average and other seasons are then assigned accordingly) temperatures of the Atlantic Water core (Fig. 4) at the BSO (see Fig. 1 for the location of the section) is constructed by averaging the temperatures higher than $3^{\circ} \mathrm{C}$ at depths below $50 \mathrm{~m}$ over a domain extending in latitude from $71.5^{\circ} \mathrm{N}$ to $73.5^{\circ} \mathrm{N}$ along the $19^{\circ} \mathrm{E}$ meridian and over one degree in longitude. In order to describe the oceanic variability farther east, seasonal temperature observations collected at the Kola section by PINRO (http://www.pinro.ru/) are used to form a time series of AW characteristics averaged between 50 and $200 \mathrm{~m}$ and $70.5^{\circ}$ and $72.5^{\circ} \mathrm{N}$. Finally, sea surface temperatures (SST) from the ERA-I reanalysis are used to characterize the ocean surface conditions associated with the Barents Sea ice distribution.

\subsection{Model simulation}

The outputs of a simulation with a regional coupled sea iceocean model are used to analyze the relationship between the SIC variability and both the sea ice growth and convergence and the AW properties and circulation. The sea ice-ocean model is based on NEMO (Nucleus for European Modelling of the Ocean) version 3.2 (Madec, 2008) coupled to the LIM2 (Fichefet and Morales Maqueda, 1997) sea ice model. The equations are discretized on 46 vertical levels with thickness varying from $6 \mathrm{~m}$ in the top layer to roughly $250 \mathrm{~m}$ at the deepest model level. Partial steps are used to 
better represent the bottom topography. Isopycnal tracer mixing is parameterized by a Laplacian operator, and a biharmonic operator is used for horizontal viscous terms. A turbulent kinetic energy closure scheme that explicitly calculates the evolution of the turbulent kinetic energy is used for vertical mixing of momentum and tracers. The domain encompasses the Arctic Ocean and the Atlantic Ocean, with open boundaries at $30^{\circ} \mathrm{S}$ in the Atlantic and $50^{\circ} \mathrm{N}$ in the Pacific, along which the velocity and tracer distributions are prescribed from the monthly climatology of a global simulation. The model grid has a horizontal resolution varying from $10 \mathrm{~km}$ in the Arctic Ocean to $25 \mathrm{~km}$ at the equator.

The model is initialized from rest with initial temperature and salinity distributions from the PHC 3.0 global ocean climatology, updated from Steele et al. (2001). The model surface forcing is based on daily surface atmospheric fields from the ERA-I reanalysis (1979-2012). Turbulent heat fluxes are computed using a

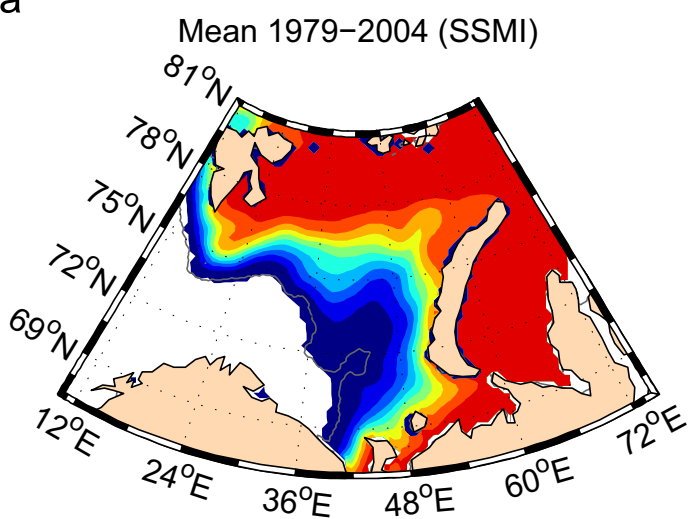

b

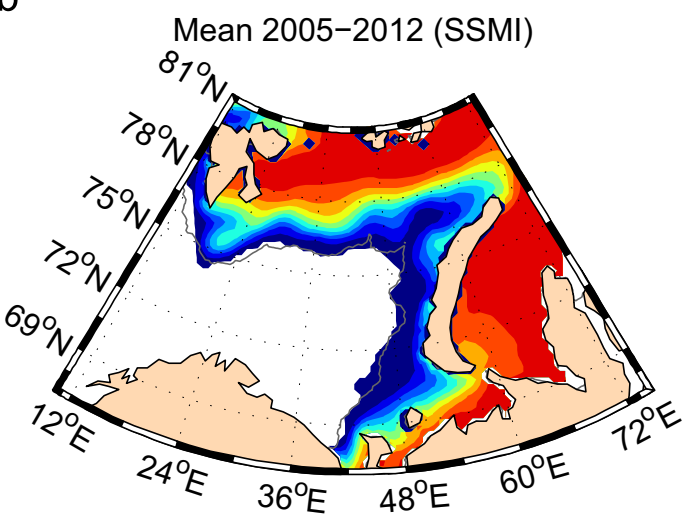

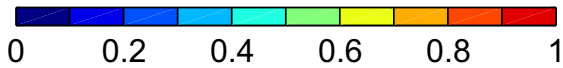

C

Standard deviation 1979-2004 (SSMI)

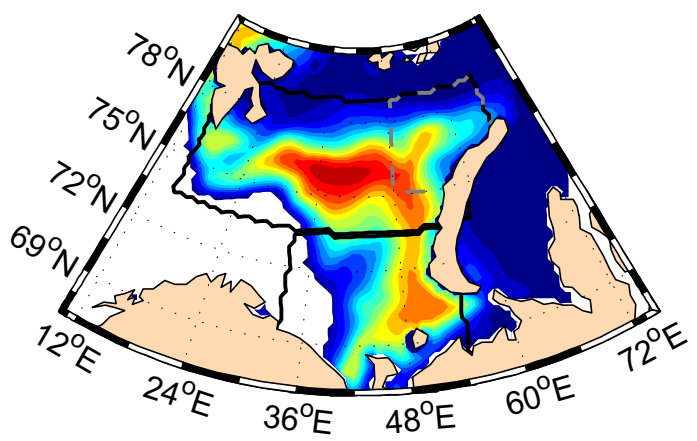

d

Standard deviation 2005-2012 (SSMI)

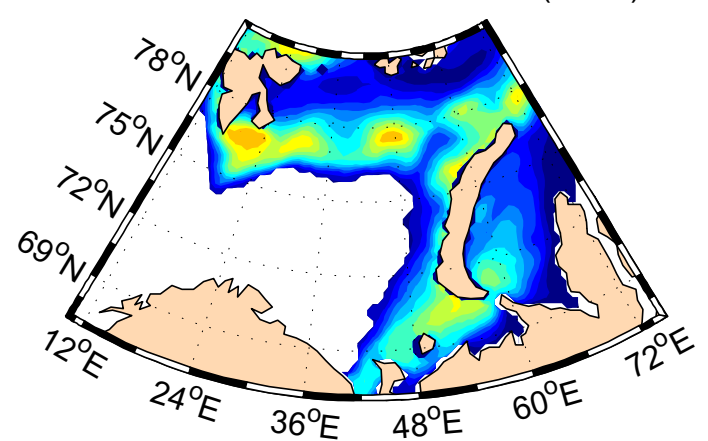

$\begin{array}{lllllllll}0 & 0.05 & 0.1 & 0.15 & 0.2 & 0.25 & 0.3 & 0.35 & 0.4\end{array}$

e Standard deviation 1979-2004 (Model)

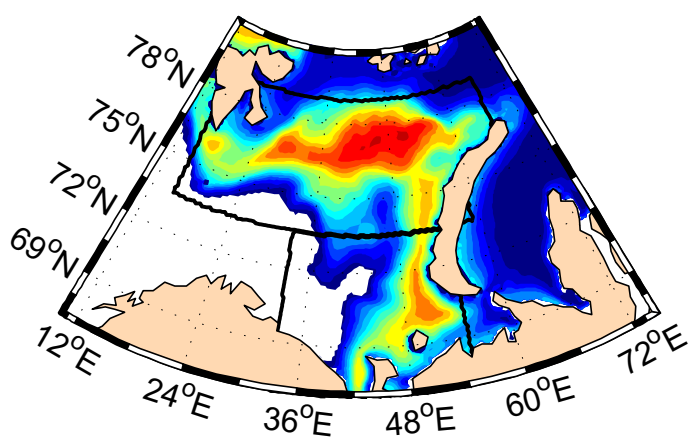

f

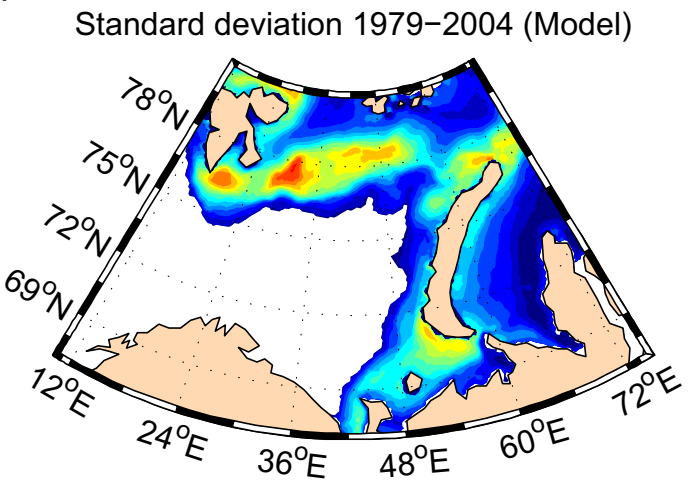

$\begin{array}{lllllllll}0 & 0.05 & 0.1 & 0.15 & 0.2 & 0.25 & 0.3 & 0.35 & 0.4\end{array}$

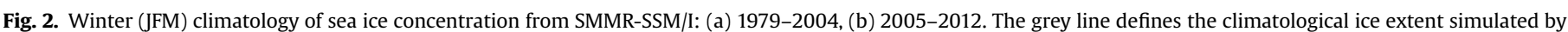

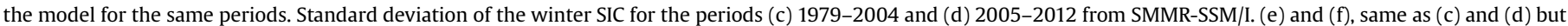

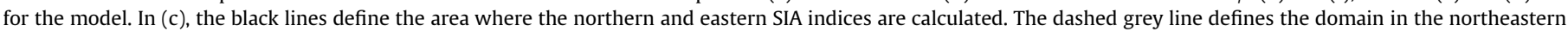

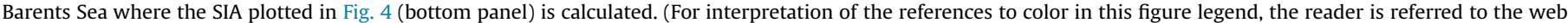
version of this article.) 
the Large and Yeager (2004) bulk formulae with daily dew point temperature, surface air temperature (SAT), wind speed and sea level pressure (SLP) as the main atmospheric inputs. Other forcing fields from the reanalysis include the wind stress and the downward radiative fluxes. Surface albedos and temperatures simulated by the model are used to calculate the upward components of the radiative fluxes. Regional corrections have been made to improve the radiation fluxes over the North Atlantic and the SAT over the Arctic. All corrections have been applied to the annual climatological cycle (obtained by averaging the daily fields between the 34 years of the reanalysis), while the field anomalies (obtained by subtracting this climatology from the original daily fields) are kept unchanged. Over the Atlantic Ocean, the ISCCP (International Satellite Cloud Climatology Project) radiation climatology (Rossow and Schiffer, 1999) is used instead of ERA-I while in the Arctic Ocean (north of Fram Strait) the ERA-I SAT climatology is replaced by the IABP (International Arctic Buoy Programme) climatology [Rigor et al., 2000] in order to remove unrealistic positive summer SAT values. The river runoff is prescribed from the monthly climatology proposed in the AOMIP protocol (http://www.whoi.edu/ projects/aomip). The salinity in the top model layer is restored to the PHC climatology with a time scale of 30 days. The model is spun up for 42 years by applying two cycles of the 1958-1978 atmospheric forcing from the ERA40 reanalysis. The conditions obtained at the end of this spin-up period are used as initial conditions for a 34-year (1979-2012) simulation forced by the ERA-I reanalysis. Results from this last simulation are used for the present analysis.

\section{Model performance in the Barents Sea}

The simulated SIC has been validated against the SMMR-SSM/I data set in the Barents Sea. The position of the mean winter sea ice edge simulated by the model follows the position derived from the satellite observations (Fig. 2a). Similar patterns of SIC variability are also found in the model and the SMMR-SSM/I observations, although in the model the northern maximum of the standard deviation is located farther north and there is less variability to the west of Novaya Zemlya (Fig. 2c and e). The simulated sea ice area (SIA) transport through a section extending from Svalbard to Severnaya Zemlya across Franz Josef Land (JFL) is, on average over the period 1992-2004, two to three times higher than the corresponding satellite estimate (Kwok, 2009). This difference is due to ice drift velocities being overestimated relative to the satellite derived estimates (downloaded from http://cersat.ifremer.fr/). Nevertheless, the time series are strongly correlated between model and observations, both for the transport between Svalbard and FJL $(R=0.91)$ and the transport between FJL and Severnaya Zemlya, $(R=0.97)$. Additionally, as will be shown in Section 4.2, the SIA transport between Svalbard and FJL (the main outlet for the Arctic sea ice to the Barents Sea) explains a similar amount of the variance of the SIA in the northern Barents Sea, in the model and in the observations (30\% and $20 \%$, respectively). In terms of ice volume transport, the relevant variable for ice budget analyses, the impact of the model biases on the ice drift velocities is likely to be partly compensated by the counteracting effect of underestimated model ice thicknesses (as deduced from a comparison with the available observational estimates obtained by Kwok and Cunningham (2008) from ICESat altimetry over the period 20032008).

In the model simulation, the main core of the mean Atlantic Water inflow is located along the southern flank of the BSO (Fig. 3a). The AW inflow feeds the Novaya Zemlya Branch, which advects AW across the southeastern region of the Barents Sea, and the Franz Josef Branch which transports AW into the northeastern
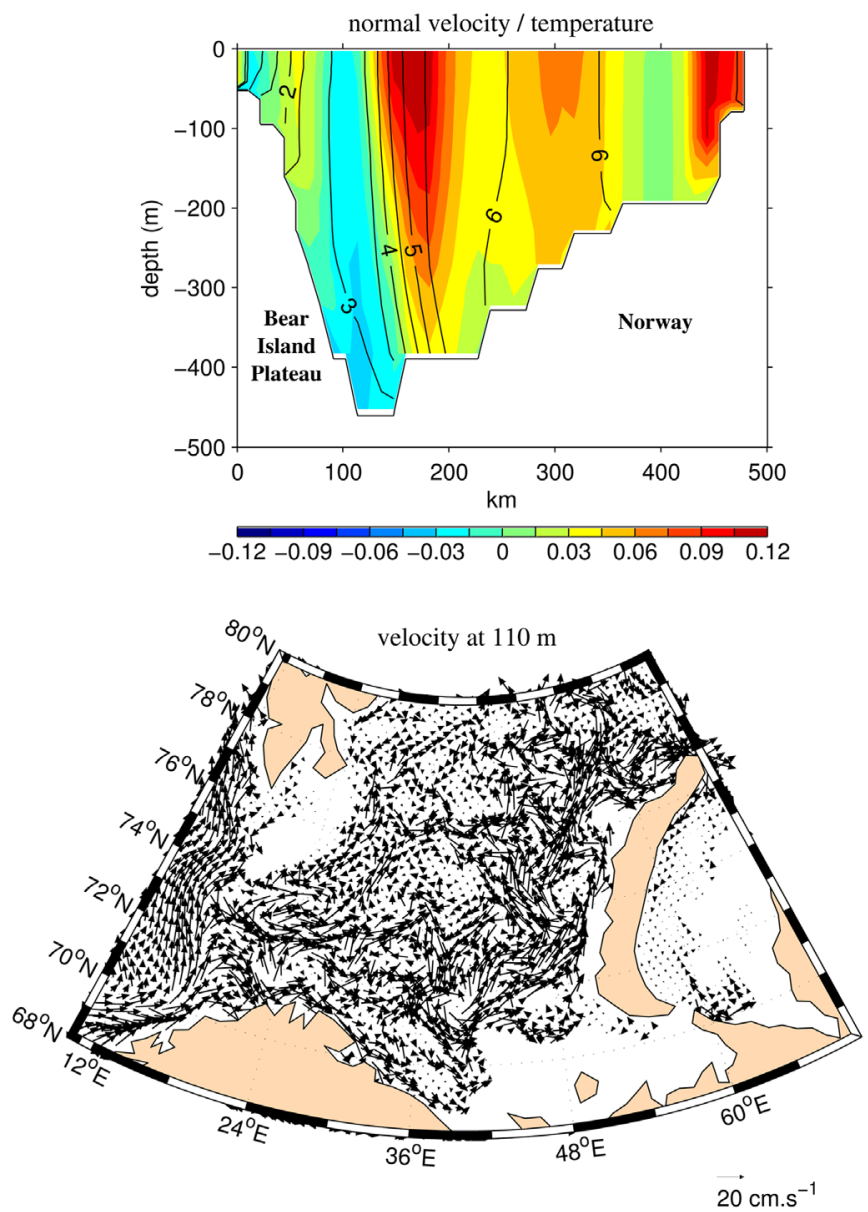

Fig. 3. (a) Mean winter eastward velocity (m/s) (color) and temperature (in ${ }^{\circ} \mathrm{C}$ ) (isolines) across the BSO simulated by the model over the period 1979-2004. The section runs southward from the Bear Island Plateau along the $19^{\circ} \mathrm{E}$ meridian. (b) Mean winter velocity at $110 \mathrm{~m}$.

Barents Sea (Fig. 3b). In the Hopen Trench, part of the Atlantic water recirculates after being cooled and exits the Barents Sea as a trapped current along the southern slope of the Bear Island Plateau (Fig. 3a). This circulation is in qualitative agreement with observations (Ingvaldsen et al., 2004; Skagseth, 2008; Lien et al., 2013). At the surface, the circulation includes coastal currents flowing along the northern Norwegian and Russian coasts (Skagseth et al., 2011), then turning along the western coast of Novaya Zemlya (Ozhigin et al., 2000). At BSO, the model simulates a net volume transport of $2 \mathrm{~Sv}$ (computed between $71.5^{\circ}$ and $74^{\circ} \mathrm{N}$ to be consistent with the observations) over 1998-2008, which is in agreement with the observational estimates available over this period (Skagseth et al., 2008, Lien et al., 2013). The outflow part of this transport also agrees with the estimate of $0.9 \mathrm{~Sv}$ obtained from mooring measurements over the period 2003-2005 (Skagseth, 2008). The net heat transport associated with the AW transport through BSO is 56 TW over the 1998-2008 period, close to the 49 TW estimated from observations (Årthun et al., 2012).

At the BSO and Kola sections, the mean seasonal cycle of the model temperatures is more pronounced than in the observations and marked by a year long positive bias of $0.5-1{ }^{\circ} \mathrm{C}$. Nevertheless, the variability (with respect to this mean seasonal cycle) is well represented. The highest correlations between the model and the observations are found in winter and spring $(R>0.8$ and $R>0.9$ for the BSO and Kola sections respectively). At both sections, the correlations are slightly lower in summer and fall $(R>0.7)$. The correlation in winter is lower $(0.68)$ when we consider only the core of the Atlantic Water, which is defined in the observations by 
a cut-off temperature of $3{ }^{\circ} \mathrm{C}$ (following Ingvaldsen et al., 2004) and by a cut-off temperature of $4^{\circ} \mathrm{C}$ in the model (taking into account the model warm bias). The simulated salinity anomalies match the observations less closely, with correlations reaching a maximum of 0.5 at the Kola section.

\section{Results}

In order to analyze the variability of the winter sea ice and its relation to the atmospheric and oceanic conditions at different periods of the year, a moving average filter with a 3-month window was applied to the monthly time series of the relevant variables. These three-month averages are used to define the four seasons (winter is attributed to the JFM average and other seasons are then assigned accordingly), while early and late seasons are defined by the same average shifted by one month ahead and after, respectively (i.e "early winter" denotes DJF, whilst "late winter" denotes FMA). For the following analysis of the sea ice variability, the SIC deduced from the SMMR-SSM/I dataset is generally used (unless otherwise specified, essentially for some model diagnoses which instead are based on the simulated SIC). Lead/lag correlations between the different variables have been calculated at time intervals of zero to several months. The significance of the correlations or regressions is estimated using either a Monte-Carlo method or $t$-test, with the degrees of freedom estimated by taking into account the autocorrelation of the time series (Bretherton et al., 1999). Unless otherwise specified, correlations are considered significant when their value is equal or larger than the threshold value corresponding to the 95\% level of confidence. All the time series have been linearly detrended for the computation of correlations and regressions.

\subsection{Two modes of interannual variability of the winter SIC}

In winter, sea ice covers the northern and eastern parts of the Barents Sea (Fig. 2a). However, a strong northward / eastward retreat has been observed since 2005, leading to significant differences between the winter SIC mean states before and after this time (Fig. 2a and b) and a change of slope in the SIA time series of the entire Barents Sea in 2005 (Fig. 4, middle panel, black line). This marked decrease of the sea ice coverage after 2004 can be detected using a regime shift detection method (Rodionov and Overland, 2005). Consistently, in Close et al. (2015) analysis of the satellite period, 2004 corresponds to the year of onset of an accelerated decline of the winter sea ice concentration in the Barents Sea. More importantly, after a piece-wise detrending of the SIC time series, we also detected a significant (based on an F-test) drop in the SIC variance after 2004 (Fig. 2c and d), most probably linked to the statistically different means between the 1979-2004 and 2005-2012 periods. The dominant patterns of the variance are also modified after 2004. While, in the first period, the maximum of the variance is centered at around $40^{\circ} \mathrm{E}$ with the northwestern Barents Sea only accounting for a small part of the variance, a different situation is observed in the second period when the maximum of the variance is shifted farther to the north and west (Fig. 2d). Due to these abrupt changes in the amplitude and distribution of the variability from 2005 onward, an investigation of the interannual variability based on the full time series was judged to be inappropriate and the two periods were instead analyzed separately. However, the results hereafter mostly concern the first period since, due to the shorter record, the second period can only be investigated qualitatively.

Over the 1979-2004 period, two maxima of SIC variability are found, one located at the northern edge of the sea ice cover and the other off the southwestern coast of Novaya Zemlya (Fig. 2c).
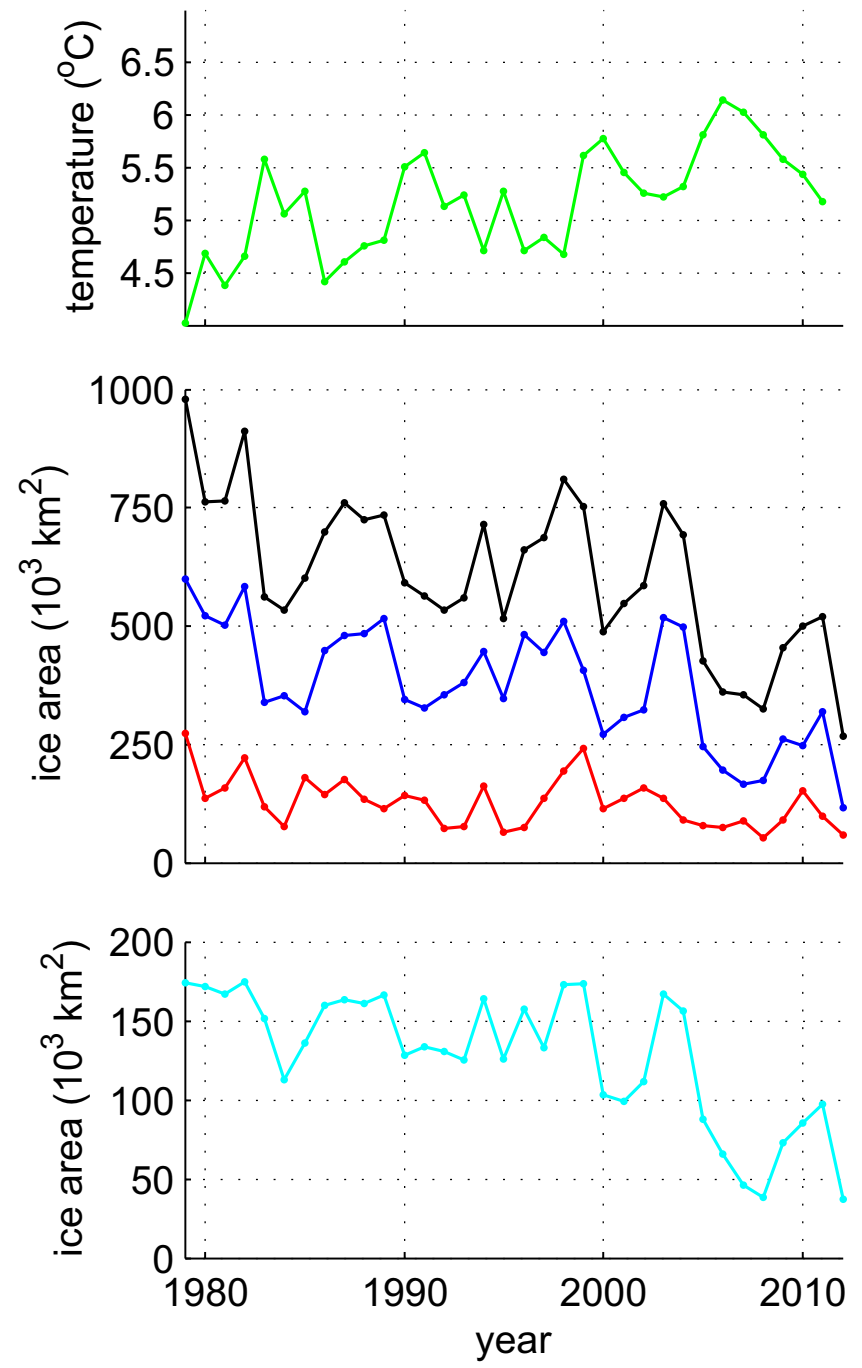

Fig. 4. Winter ocean temperature averaged between 50 and $200 \mathrm{~m}$ at BSO from observations (top panel). Winter sea ice area (SIA) computed from the SMMR-SSM/I dataset for the entire Barents Sea (black), the northern Barents Sea (blue) and the southeastern Barents Sea (red) (middle panel) and the northeastern Barents Sea (bottom panel). The blue and red time series in the middle panel are used to generate time series of detrended SIA anomalies corresponding to the northern and eastern SIA index, respectively. The different SIA regions are shown in Fig. 2c. (For interpretation of the references to color in this figure legend, the reader is referred to the web version of this article.)

Two separate indices of the winter sea ice variability, hereafter referred to as the northern and eastern SIA indices, have therefore been constructed by summing the winter SIC over two regions encompassing these maxima (see Fig. $2 \mathrm{c}$ for the geometry of the two regions) and taking the anomalies of the calculated SIA with respect to the 1979-2004 average. Additionally, a separate subregion was defined as the easternmost part of the region represented by the northern index (Fig. 2c). Neither the trends in the two indices, nor the simultaneous correlation between the two indices are significant. Separate regressions of the SIC anomalies onto the two indices indeed show distinct patterns (Fig. 5a and b), suggesting two different modes of SIC variability. The high correlations between the sea ice extent and the SIA in each of the two domains indicate that both modes are associated with a displacement of the ice edge, with the northern mode representing the latitudinal displacement of the northern ice edge and the eastern mode being associated with variations in the sea ice coverage in the shallow areas of the southeastern Barents Sea. Two similar patterns are also obtained with a rotated EOF analysis 
a

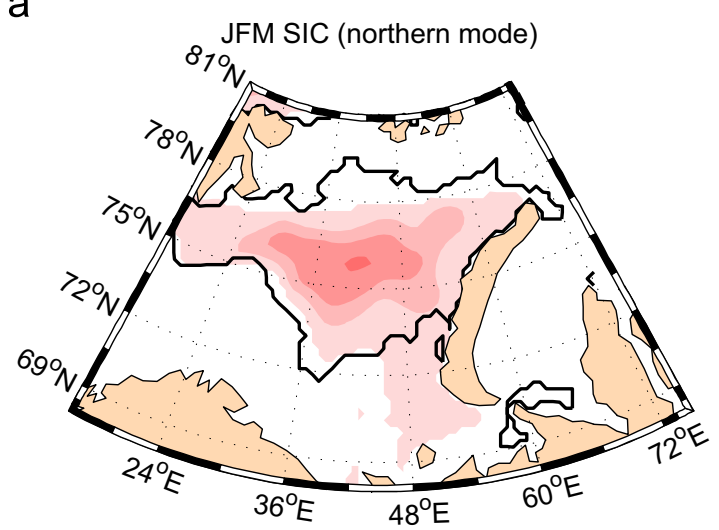

C

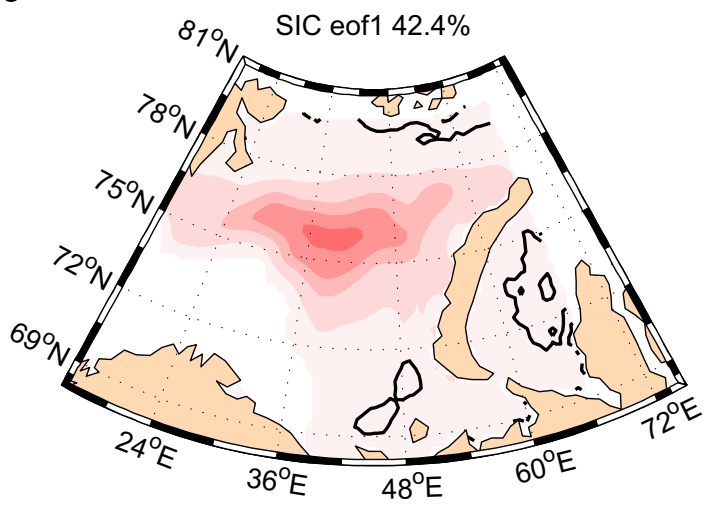

b

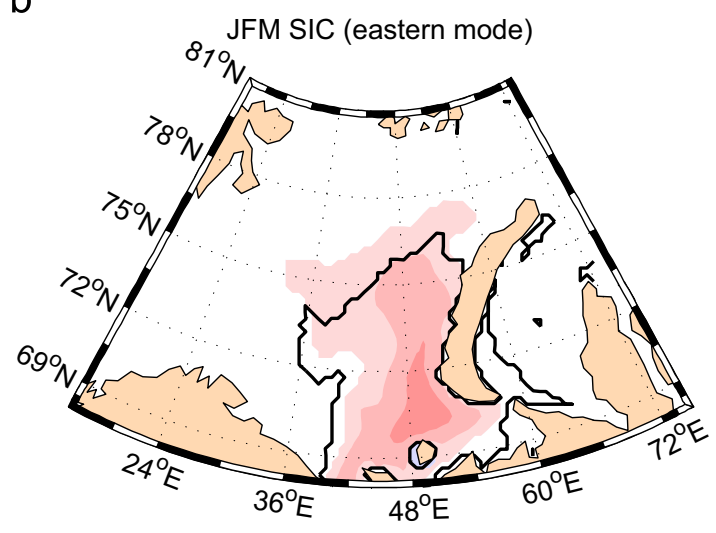

d

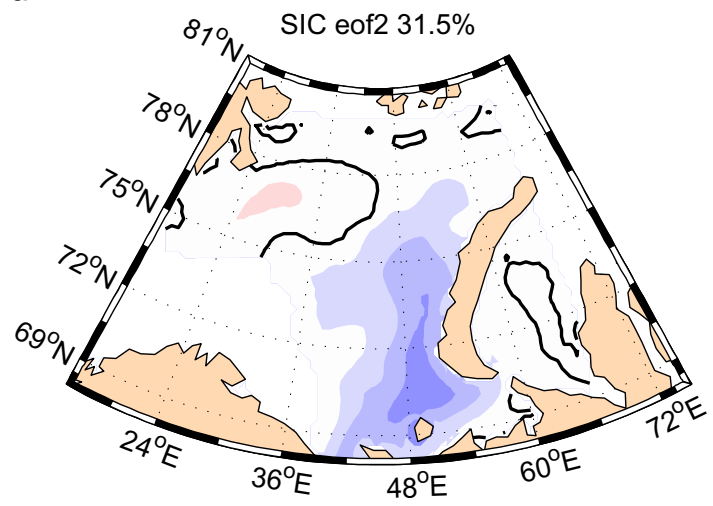

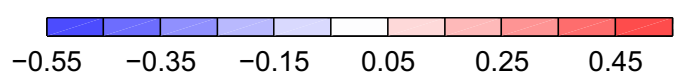

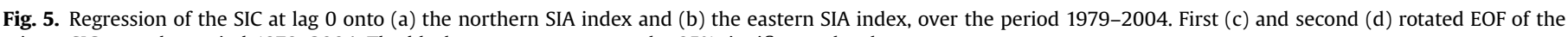
winter SIC over the period 1979-2004. The black contour represents the 95\% significance level.

(Fig. $5 \mathrm{c}$ and d) of the winter SIC anomalies, with the first (second) modes representing $42 \%$ (31\%) of the variance and the first (second) principal components correlating at 0.92 (0.97) with the northern (eastern) SIA indices. It is therefore of interest to analyze separately the mechanisms underpinning these two distinct modes of variability. Note however that the domain of the northern SIA mode covers a larger area and, as such, its variability dominates that of the entire Barents Sea as evidenced by the high correlation (0.91) between the northern SIA index and the SIA of the entire Barents Sea (Fig. 4).

\subsection{Statistical links between the northern SIA index and the surface atmosphere}

In order to investigate the relationship between the northern SIA index and the atmosphere, lagged correlations between atmospheric surface fields (wind, SAT, SLP) and the index have been calculated. The strongest correlations between the northern SIA index and the wind are obtained with the meridional (as opposed to zonal) component and when the wind leads the ice by 1 month (a maximum correlation of 0.83 is obtained between the index and the DJF northerly wind anomalies). The early winter wind pattern associated with positive values of the SIA index shows northwesterly wind anomalies in the vicinity of the northern ice edge (Fig. 6a) which are linked to a dipole of SLP anomalies comprising a negative pole centered over Severnaya Zemlya and extending eastward over Siberia, and a positive pole over the Greenland Sea (Fig. 6c). This SLP dipole pattern is different from the Arctic
Oscillation (AO) pattern, and, consistently, the AO index and the northern SIA index are found not to be significantly correlated. The SLP dipole is associated with a strong SLP gradient to the east of Svalbard. More precisely, the early winter SLP anomalies calculated relative to the area mean SLP over Svalbard show maximum $(R=0.85)$ correlation with the northern SIA index in a region centered over Severnaya Zemlya (Fig. 7a). This correlation pattern highlights the importance of the SLP anomalies over this region. The correlation is slightly lower $(R=0.80)$ over Novaya Zemlya. As for the wind, the surface air temperature (SAT) displays the strongest anticorrelation (maximum correlation $R=-0.92$ ) with the northern SIA index when it leads the sea ice by 1 month. The early winter SAT correlation on the northern index displays a pole centered over the Barents Sea (Fig. 6d) which would be consistent with cold air being advected by northwesterly wind anomalies associated with enhanced sea ice coverage in the northern Barents Sea. Another possibility would be that SAT anomalies are driven by air-sea heat flux anomalies generated by changes in the ice-ocean surface temperature.

The significant correlations between the northern SIA index and the magnitude of the SLP gradient east of Svalbard extend back to the previous fall (Fig. 7a), suggesting that the response of the winter SIA in the northern Barents Sea integrates the effect of wind-driven processes occurring in this area during the previous season. The relationship extends farther back to the previous winter, and is even stronger at this time if the SLP gradient is evaluated between Svalbard and Novaya Zemlya (in this region, a secondary maximum appears in the previous winter and early 
a

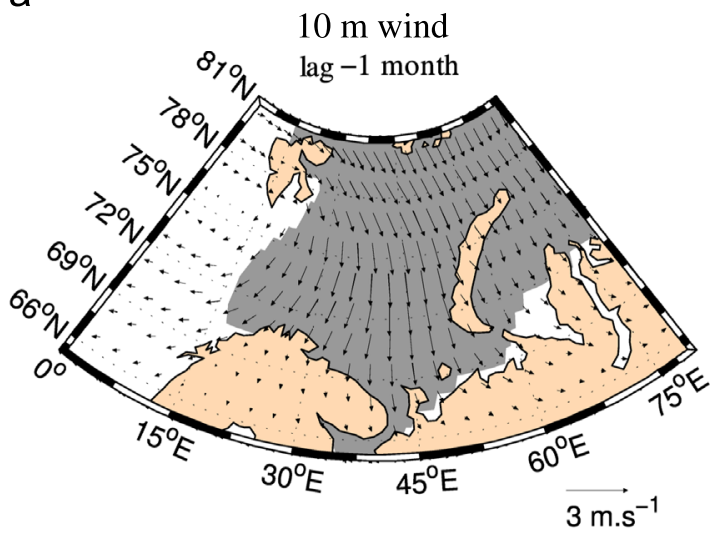

C
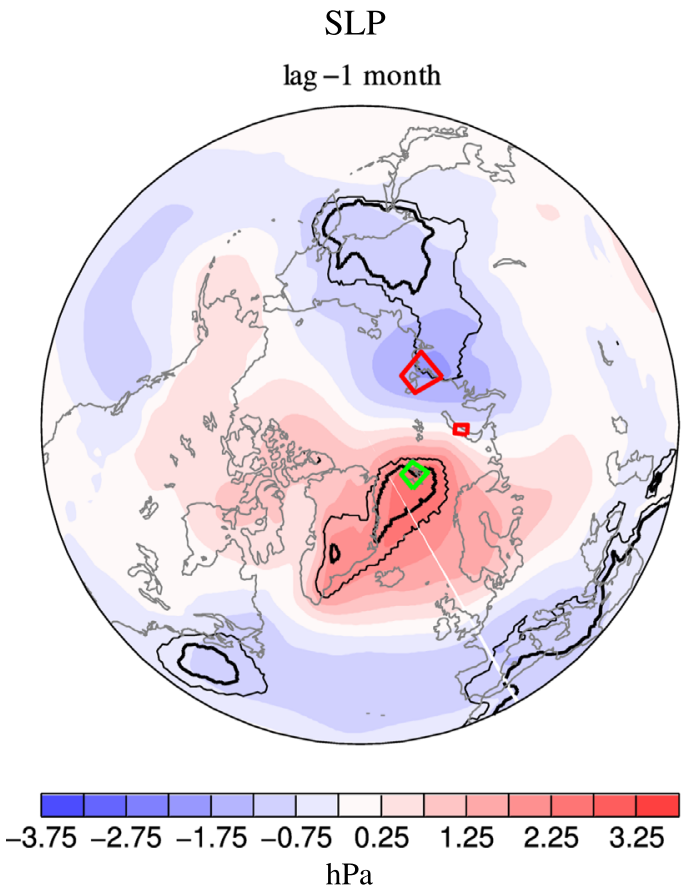

b

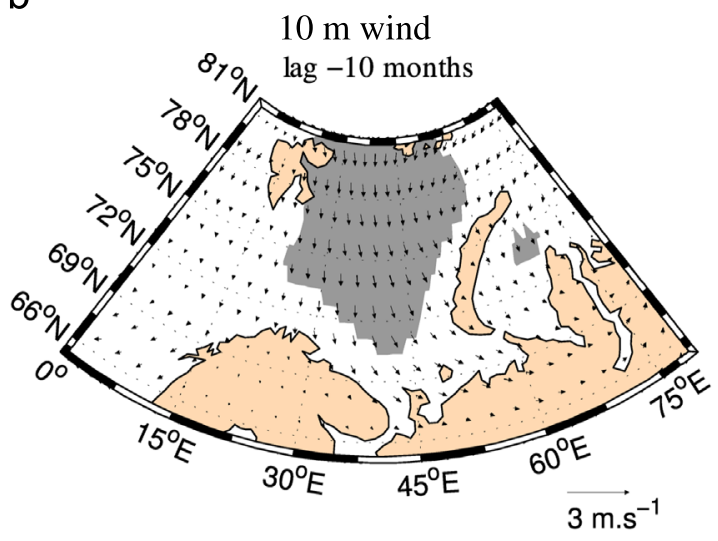

d

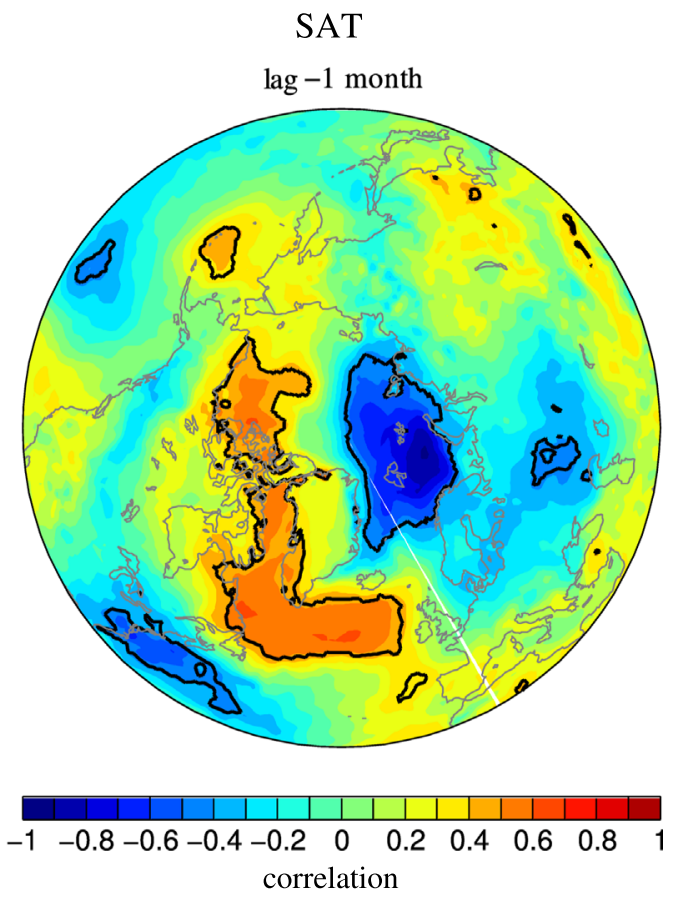

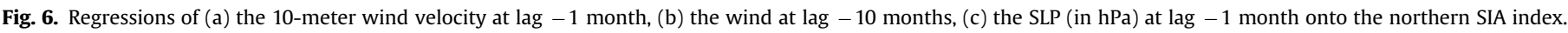

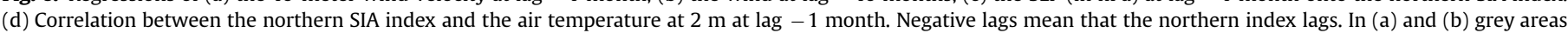

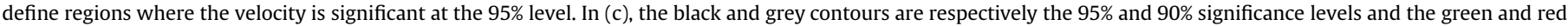
boxes define the area where the SLP has been averaged (see explanation in the text). Correlations and regressions have been computed over the period 1979-2004.

spring in the correlations shown in Fig. 7a). The surface wind anomaly patterns associated with the SIA variability of the northern Barents Sea at lag -1 month and -10 months are quite similar, except that wind anomalies appear more meridional in the latter case (Fig. 6a and b). As for the wind, the SAT in winter and early spring also shows significant lead anticorrelation with the northern SIA index in the following winter, suggesting that at least part of the SAT variability may be related to intrusions of cold Arctic air masses transported by the concomitant meridional wind anomalies.

Results from a regional coupled ice-ocean model can help identify the processes responsible for the strong link between the SIA in the Barents Sea and the surface atmosphere. The feasibility of this approach was verified by testing the consistency between the SIA indices calculated from the observations and those calculated using the simulated SIC. The latter were calculated over the model subdomains shown in Fig. 2e. The observed and simulated SIA indices evolve similarly, with correlations between the two sets of indices reaching up to 0.96 and 0.99 for the northern and eastern SIA indices respectively. In order to better understand the sea ice evolution, we considered the sea ice volume budgets integrated over the northern and eastern domains and calculated the separate contributions of the net ice production and convergence to these budgets. In view of the strong correlation of 0.88 (0.98) between the simulated ice volume averaged over the northern (eastern) domain and the simulated northern (eastern) SIA index, the model SIA indices have been used in the following regression analysis.

The correlations of the net ice production and ice convergence with the northern SIA index indicate that enhanced sea ice cover would occur as a result of an increase of the ice convergence, rather than net ice production (Fig. 8). Increased ice convergence is mainly fed by an enhanced sea ice transport between Svalbard and Franz Josef Land. Both quantities are significantly correlated with the northern SIA index throughout the fall-winter period, with a maximum correlation at lag -1 month (Fig. 8). A similar link between the northern SIA index and the annual mean ice area flux between Svalbard and Franz Josef Land is found in the 


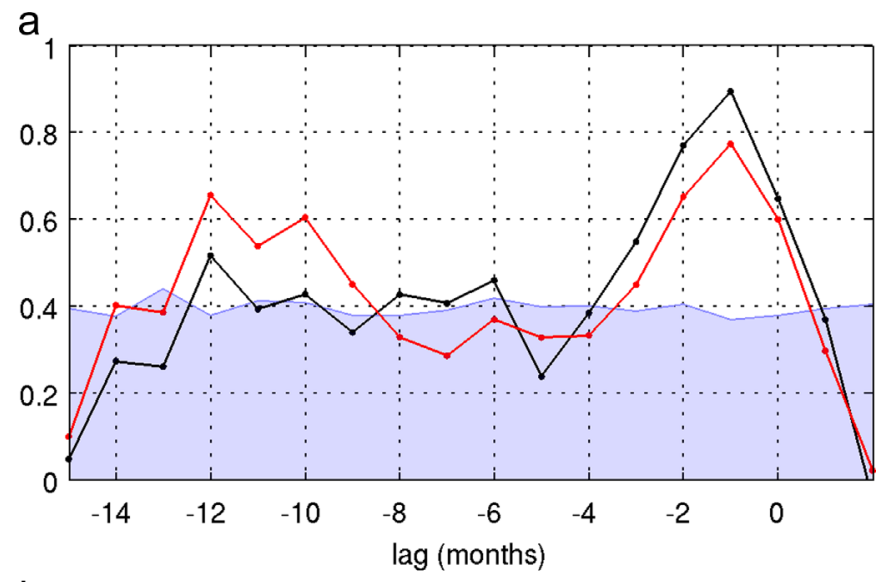

b

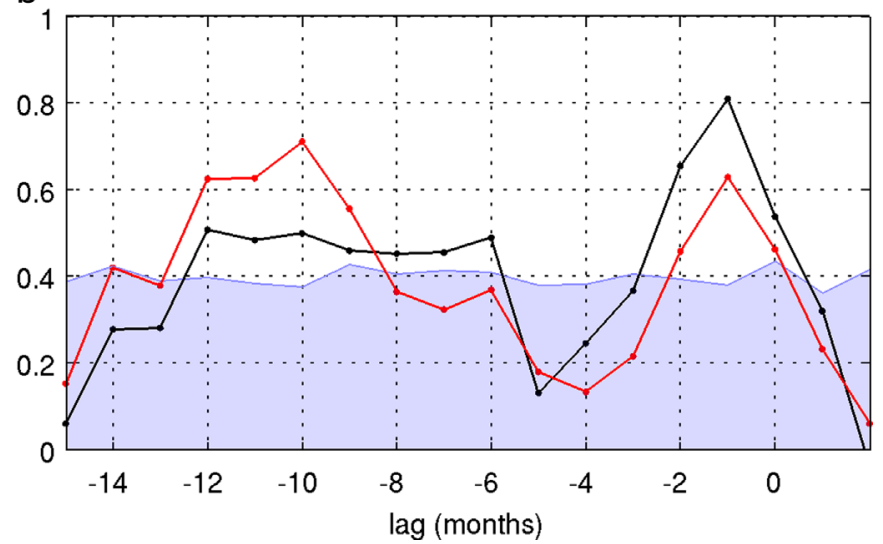

Fig. 7. (a) Correlation between the northern SIA index and the SLP difference between Severnaya Zemlya and Svalbard (black), and Novaya Zemlya and Svalbard (red). (b) Correlation between the SIA of the entire Barents Sea and the SLP difference between Severnaya Zemlya and Svalbard (black), Novaya Zemlya and Svalbard (red). The shaded area represents the 95\% significance level. Lags are counted as positive when the SIA index leads. (For interpretation of the references to color in this figure legend, the reader is referred to the web version of this article.)

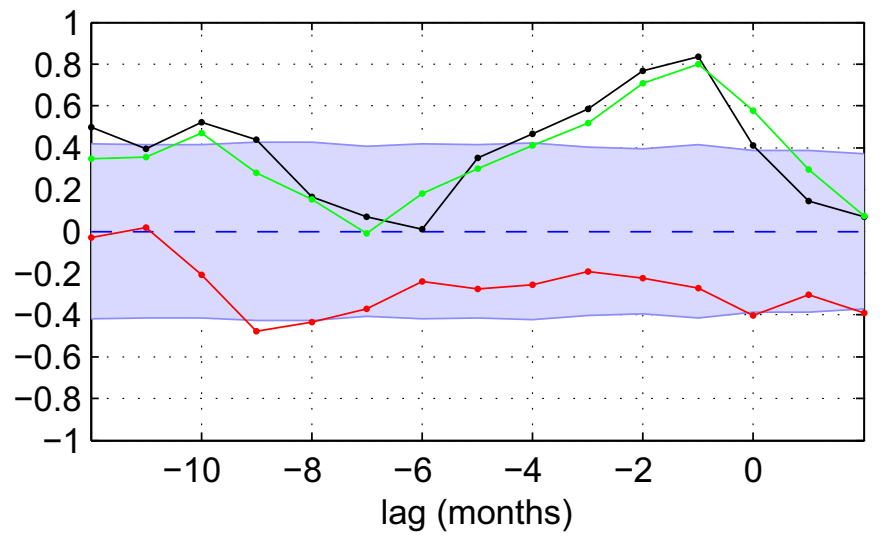

Fig. 8. Model lagged correlations between the northern SIA index and the net ice convergence (black), the net ice production (red), and the ice volume transport through the passage between Svalbard and Franz Josef Land (green). The shaded area represents the 95\% significance level. Lags are counted as positive when the SIA index leads. (For interpretation of the references to color in this figure legend, the reader is referred to the web version of this article.)

observations $(R=0.44)$. This result suggests that the almost inphase relationship identified at the interannual time scale between the winter sea ice cover in the northern Barents Sea and the meridional wind intensity would be effected by wind driven

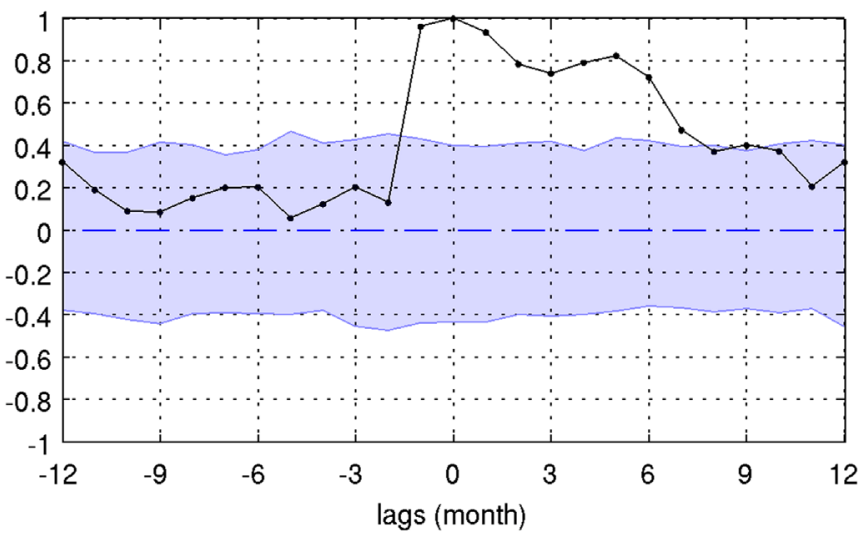

Fig. 9. Correlation of the northern SIA index with the monthly SIA in the northern Barents Sea. Monthly SIA are calculated over the same domain as the northern SIA index. The shaded area represents the $95 \%$ significance level. Lags are counted as positive when the northern SIA index leads.

anomalies of the sea ice export from the Arctic Ocean. Similarly, the export of polar water from the Arctic through the same passage in the model exhibits significant, almost in-phase (in winter and in late fall) correlations with the northern SIA index, reaching a maximum of 0.73 when the export leads by 1 month, suggesting that concomitant anomalies of the liquid and solid fresh water export are involved in the sea ice cover variability in this region. Enhanced fresh water export from the Arctic would increase the surface stratification, suppressing mixing with the warmer deep layers and thus promoting ice growth.

\subsection{Role of the ocean in the winter sea ice variability in the northern Barents Sea}

The significant correlation between the atmosphere and the northern Barents Sea ice when the former leads by several (up to 12) months strongly suggests that ocean or sea ice processes forced by common atmospheric patterns must be involved in the sea ice response. Persistence of winter or spring SIA anomalies until the following winter can be discounted as a possible mechanism since, as shown in Fig. 9, correlations of the winter or spring northern Barents Sea SIA with the SIA of the following seasons are only marginally significant for seasons beyond summer. A similar conclusion can be drawn based on model results for the correlation of the winter or spring ice thickness anomalies in this region with the SIA of the following seasons. On the other hand, the major heat source to the Barents Sea in winter is provided by the AW flow through the BSO.

\subsubsection{Transports through BSO}

The available observational time series of the heat transport through BSO suggest a link with the sea ice variability over the last decade (Årthun et al., 2012), but the observational time series is shorter than the period used here, and not sufficiently long to permit a robust evaluation applicable to our longer time period. Using output from our simulation, we calculated the heat transport (relative to the reference temperature of $0{ }^{\circ} \mathrm{C}$ ), and found significant correlations between the net heat transport through BSO and the northern SIA index. Although the simultaneous correlations are significant, the strongest correlation occurs in late fall ( -0.67 at lag -2 months) (Fig. 10a, black curve). The correlations are mainly supported by the inflow branch (Fig. 10a, green curve), with the exception of the simultaneous correlation, which rather expresses a link with the variability of the outflow branch (Fig. 10a, red curve). A more extensive sea ice cover is indeed accompanied by a simultaneous increase of the outflow branch at BSO, while 
a

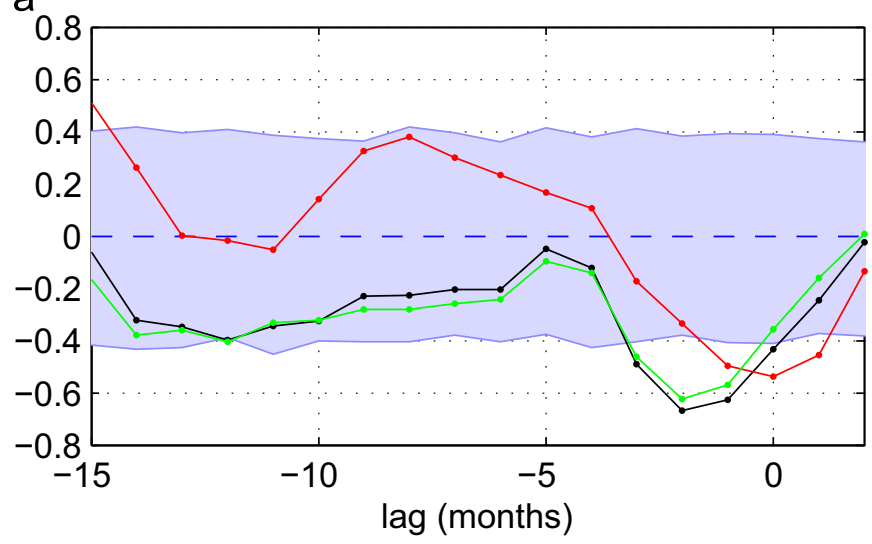

b

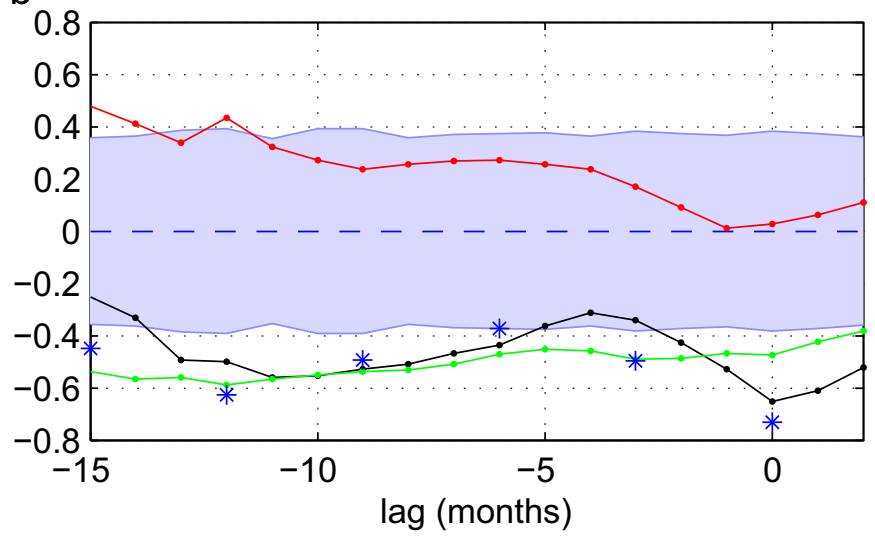

Fig. 10. (a) Correlation of the model northern SIA index with the net heat transport (black), the heat transport associated with the Atlantic inflow (green) and outflow (red) between Norway and Bear Island. (b) Correlation between the northern SIA index and the ocean heat content of the southwestern Barents Sea (black), the accumulated contributions of the surface heat fluxes (red) and horizontal ocean advection (green) to this heat content. Correlation between the northern SIA index (calculated from the SMMR-SSM/I data set) and the observed seasonal temperatures of the Atlantic Water at BSO (blue stars). The shaded area represents the $95 \%$ significance level. Lags are counted as positive when the northern SIA index leads. (For interpretation of the references to color in this figure legend, the reader is referred to the web version of this article.)

being preceded at lag -2 months by a reduction of the inflow branch. Note that in both branches the contribution of advection of temperature anomalies is comparatively small so that the correlation of the sea ice with the heat transports mainly reflects the impact of changes in the volume transports.

Despite the in phase response noted above, the correlations between the heat transport through BSO and the northern SIA index do not persist beyond 3 months. In particular, no significant correlations are found between the net heat transport or the heat inflow/outflow through BSO and the sea ice when the former leads the latter by 10 to 12 months, which is the time when we observe a significant link between the surface wind and the sea ice. This lack of correlation must imply a more complex link between the AW flow and the northern Barents Sea ice, which we investigate based on the temperature variability in the AW core.

\subsubsection{Atlantic water temperature anomalies in BSO}

Using the time series of AW core temperatures observed at BSO in winter (Section 2, Fig. 4), significant anticorrelation is found with the northern SIA index (Fig. 10b, star symbols). However, the evolution of the correlation at increasing lags is somewhat different from that obtained with the heat transport. In particular, the anticorrelation with the AW temperature is maximum $(R=-0.75)$ a

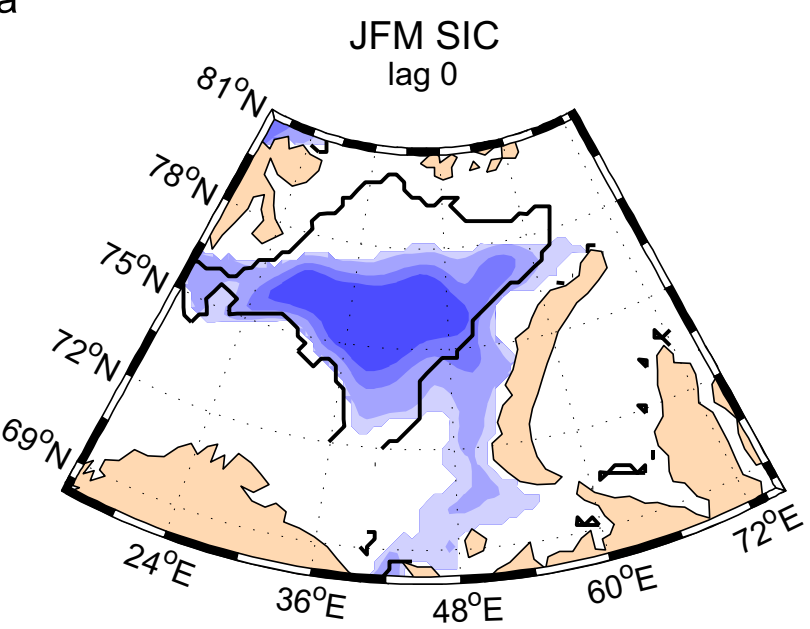

b

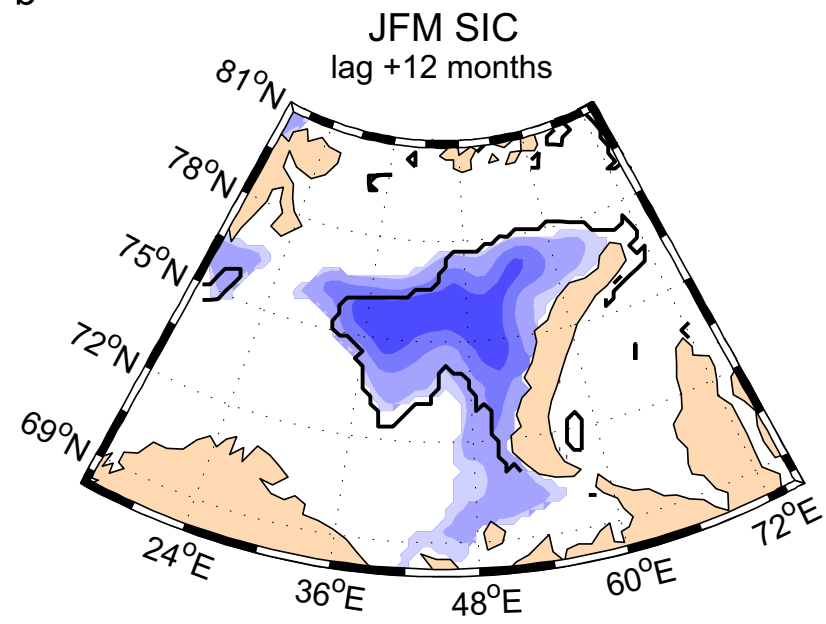

C

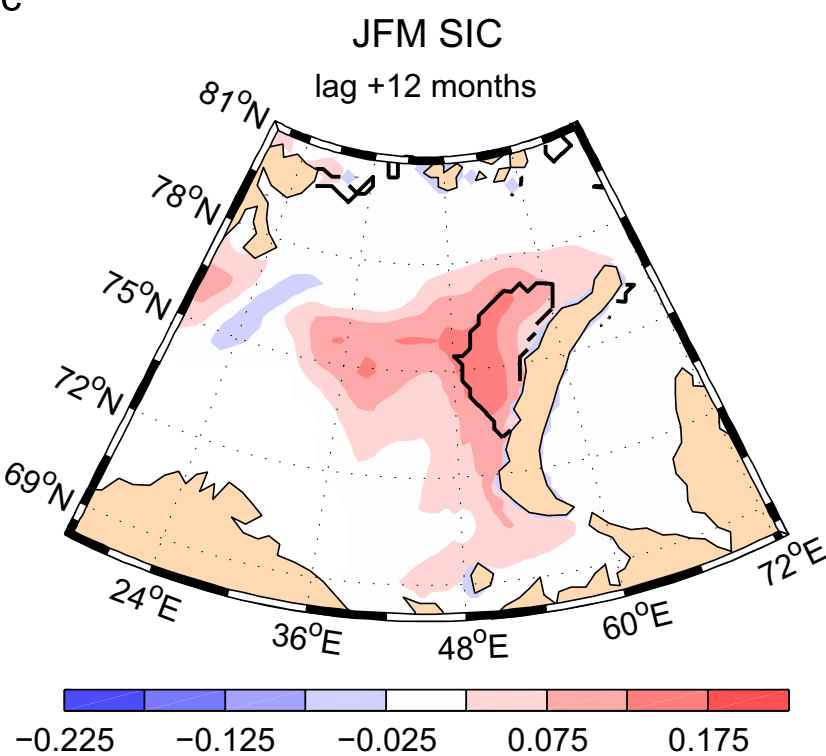

Fig. 11. Regression of the SIC (from SMMR-SSM/I dataset) (a) at lag 0 and (b) at lag +12 months onto the observed AW temperature at BSO over the period 1979-2004 and (c) at lag +12 months onto the northern SIA index. The black contour represents the $95 \%$ significance level.

at lag 0 and, although vanishing in summer, becomes significant again in the preceding spring and winter. The sea ice region which is the most influenced by the AW can be identified by regressing 
a

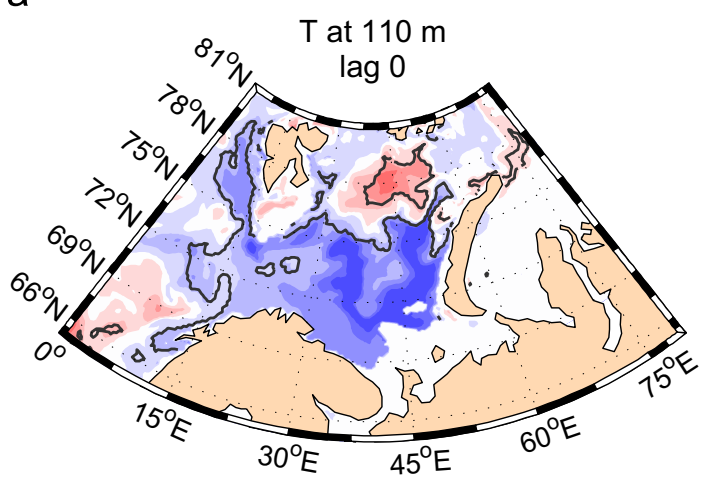

b

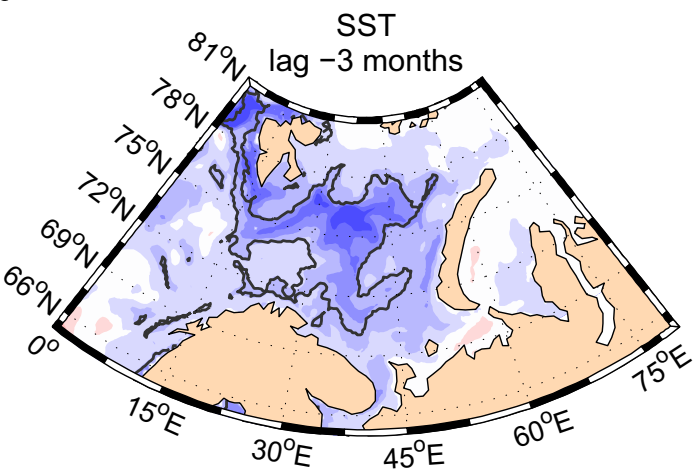

\begin{tabular}{|l|l|l|l|l|l|l|l|l|}
\hline & & & & & & & & \\
\hline-0.55 & -0.35 & -0.15 & 0.05 & 0.25 & 0.45
\end{tabular}

C

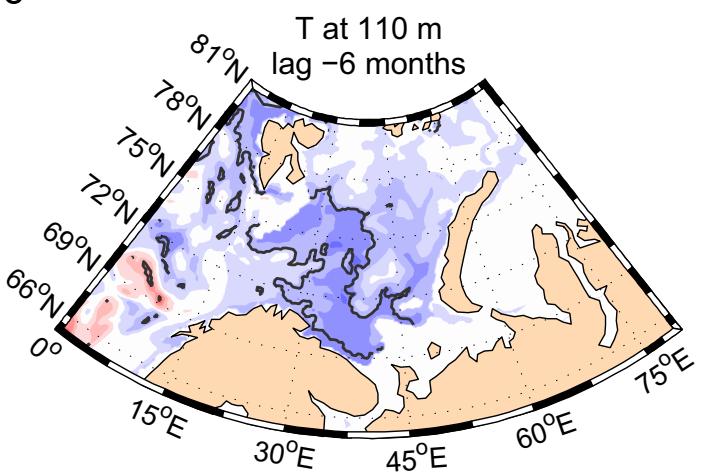

d

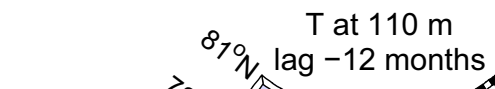

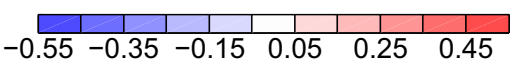

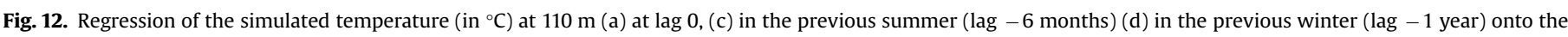

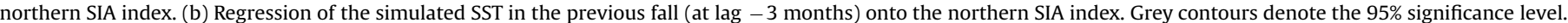

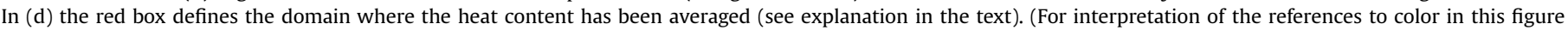
legend, the reader is referred to the web version of this article.)

the SIC onto the winter AW temperature time series shown in Fig. 4 for different lags. Note that the winter season is selected as it is the season when the AW temperature shows the strongest lagged correlation with the northern SIA index. At lag 0, the regression pattern (Fig. 11a) resembles that of Fig. 5a, as anticipated from the high correlation between the northern SIA index and the AW temperature at BSO (Fig. 10b). More interestingly, the SIC pattern at lag +1 year (Fig. 11b) is shifted eastward with respect to the pattern at lag 0 and is located over the path of the Franz Josef Branch of the AW current (Fig.1). These results suggest that the AW temperature anomalies originating in the BSO region later influence the sea ice mostly in the northeastern Barents Sea after being transported by the Franz Josef Branch across the Barents Sea.

\subsubsection{Formation and propagation of $A W$ temperature anomalies in} the Barents Sea

In order to better understand the mechanisms leading to the observed AW temperature variability over the Barents Sea, the ocean temperature anomalies simulated by the model have been regressed onto the model northern SIA index. At lag 0, the negative temperature anomalies which are observed in the BSO are part of a wider signal extending from the surface to the bottom and across the southern Barents Sea, with the strongest anomalies located along the path of the Atlantic Water (Fig. 12a). ${ }^{1}$ The

\footnotetext{
${ }^{1}$ Note that to the southwest of FJL, a small region of positive temperature anomalies develops below $50 \mathrm{~m}$ concomitantly with enhanced sea ice coverage
}

significant AW temperature anomalies in the southern Barents Sea begin to develop in the preceding fall (lag -3 months), with a strong signature extending from the surface (Fig. 12b) down to the bottom. The anomalies, however, do not extend as far west into the BSO region, suggesting that the preceding fall temperature anomalies are not directly linked to the concomitant increase of the heat inflow through the opening (Fig. 10a). As the ocean lead time increases backward from the previous fall to the previous winter, the pattern of significant AW temperature anomalies is indeed shifted closer to BSO; in the previous winter, these anomalies are confined to the western Barents Sea (Fig. 12d). As anticipated from the correlations in Fig. 10a, these initial temperature anomalies are not associated with significant changes in the heat transport through BSO. The time evolution of the patterns (Fig. $12 \mathrm{~d}$, c and a) suggests that in the following seasons, temperature anomalies are advected eastward from the western Barents Sea source region. Whereas initial temperature anomalies develop throughout the water column in winter, in the following summer, restratification of the upper layers favors recapping of the anomalies which thus disappear at the surface (not shown), but

\section{(footnote continued)}

(Fig. 12 a), while at the surface, temperature anomalies are negative and associated with negative anomalies of salinity and density (not shown). These surface anomalies may be the result of enhanced advection of Arctic water between Svalbard and FJL (as already discussed in Section 4.2), which would enhance the stratification, reduce vertical mixing and create positive temperature anomalies underneath. 
persist at depth (Fig. 12c). Recapping of the anomalies during the summer season allows their preservation at depth and their subsequent re-emergence at the surface in the following fall through vertical mixing and entrainment into the mixed layer. This process may explain the pattern of negative SST anomalies observed in fall prior to enhanced subsequent winter ice coverage (Fig. 12b).

In order to determine the origin of the temperature anomalies in the southwestern Barents Sea, the heat budget of an ocean domain defined by the region shown in Fig. 12d and extending from the surface to the bottom has been calculated in the model simulation and used as an index of the temperature variability in the BSO region. The simulated temperatures averaged over this domain are very well correlated in phase $(R=0.88)$ with the temperature observed at BSO (Fig. 4 top panel) and their variances are identical. Additionally the model temperature index and the observed temperature explain a similar amount of variance of the SIC in the northeastern Barents Sea in the model and in the observations, respectively. All these results suggest that the selected domain provides an adequate model estimate of the observed temperature variability at BSO. The total heat content of the domain has been compared with the respective contributions of the lateral heat advection and atmospheric surface heat fluxes, with both diagnostics being integrated in time and over the domain boundaries (note that the budget is not exactly balanced, but the residual is small relative to the heat content change). The correlations of each individual contribution with the northern SIA index suggest that, at any given lag, the AW temperature anomalies which influence the SIA in the northern Barents Sea are those formed as a result of anomalies in lateral heat transport convergence, rather than surface heat flux (Fig. 10b). The strongest anticorrelation between the lateral heat transport convergence and the northern SIA index occurs when the former leads the latter by 1 year (i.e in the previous winter, a season in which the heat content also shows significant anticorrelation with the index). To establish the source of the anomalies in the lateral heat transport convergence (or equivalently the ocean heat content) in the southwestern Barents Sea, temperature and velocity anomalies have been regressed separately onto the time series of the winter heat content. The in phase AW temperature anomalies highlight a significant pattern that extends into the West Spitzbergen Current and the Norwegian Atlantic Current (Fig. 13a). Note that the similarity between Figs. 13a and 12a suggests that, as for the AW temperature, the heat content in the southwestern Barents Sea and the SIC in the northern Barents Sea vary concomitantly in winter. However, the lagged regressions of the AW temperature onto the heat content (not shown) do not show propagation of a signal from the Nordic Seas into the Barents Sea. Instead, the regression of the in phase currents at $110 \mathrm{~m}$ reveals that warming of the western Barents Sea is accompanied by significant strengthening of both the southern branch of the Atlantic inflow at BSO and the Novaya Zemlya Branch (Fig. 13b), suggesting that regional circulation changes make some contribution to the variations of the heat content in the western Barents Sea.

The regression of the wind onto the heat content of the southwestern Barents Sea (Fig. 13c) shows a pattern of anomalies which is very similar to the pattern shown in Fig. 6b. Accordingly, wind anomalies with a strong meridional component drive concomitant SIA anomalies in the northern Barents Sea and, through changes in the lateral heat transport convergence, temperature anomalies in the western Barents Sea. These temperature anomalies would then propagate eastward into the Barents Sea and influence the SIA in the northern Barents Sea in the following winter. This scenario is consistent with the significant 1-year lagged correlation between the winter meridional wind anomalies and the SIA in the northern Barents Sea in the following winter that was highlighted in Section 4.2.

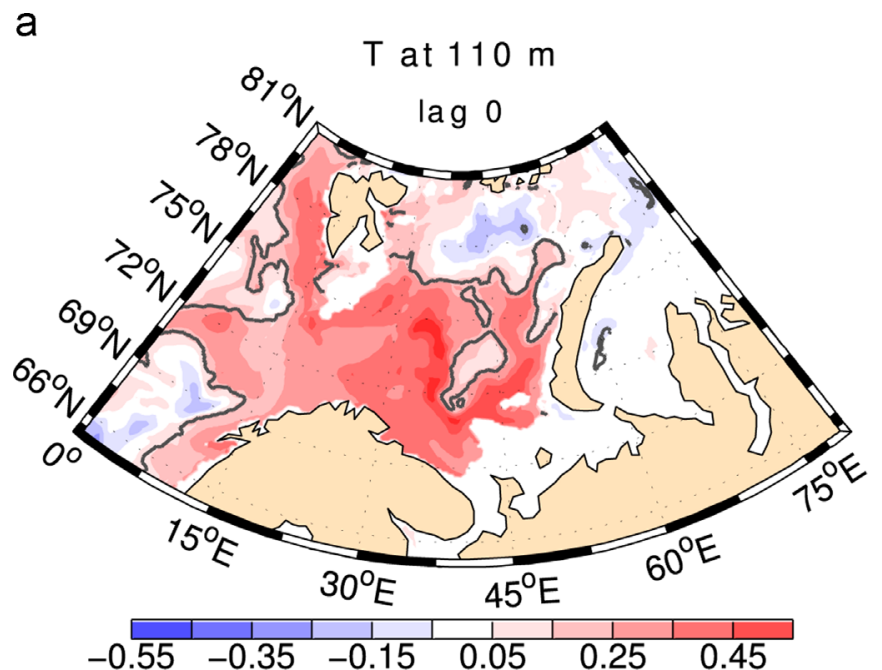

b
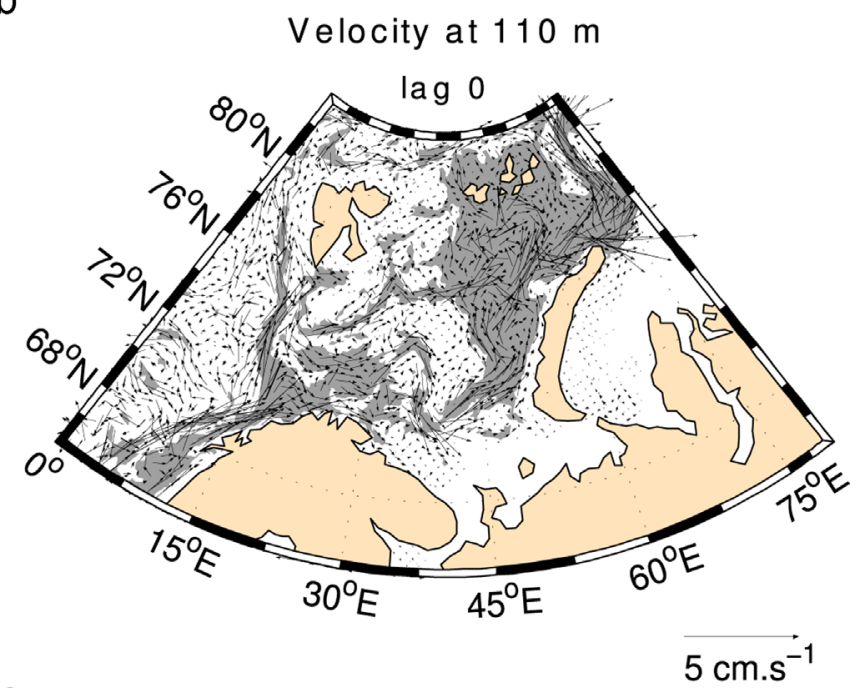

C

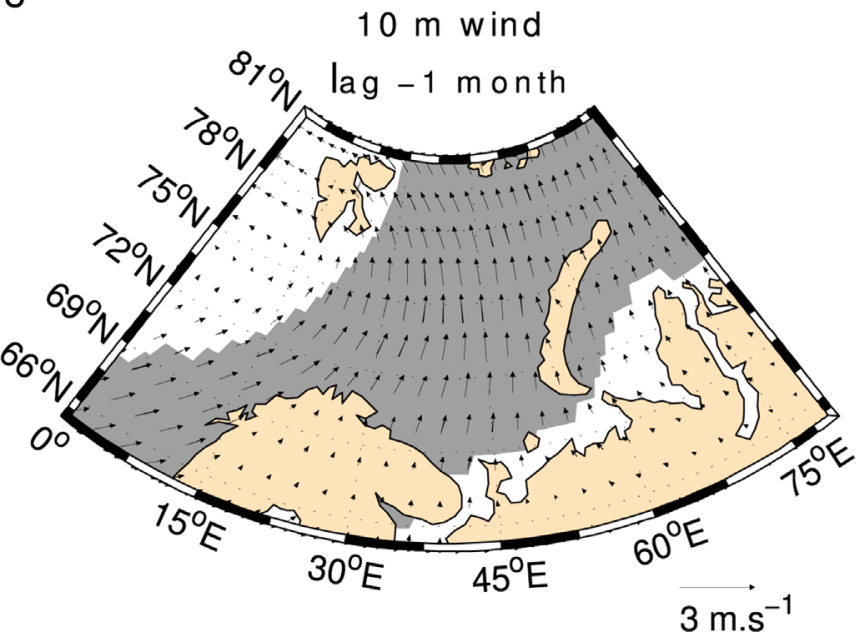

Fig. 13. Regression of the (a) temperature $\left(\right.$ in $\left.{ }^{\circ} \mathrm{C}\right)$, (b) velocity at $110 \mathrm{~m}$ and (c) $10 \mathrm{~m}$ wind velocity onto the heat content of the southwestern Barents Sea at lag 0. Black lines in (a) and grey shading in (b) and (c) represent the 95\% significance level.

\subsection{Variability of the eastern mode of SIC}

The strongest correlation $(0.82)$ between the wind and the eastern SIA index occurs with the westward component when the wind leads by 1 month. Accordingly, the regression of the surface 
a

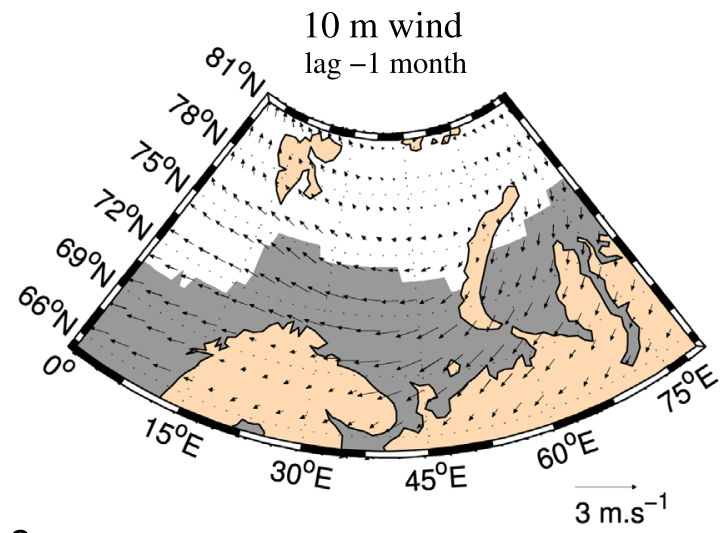

C
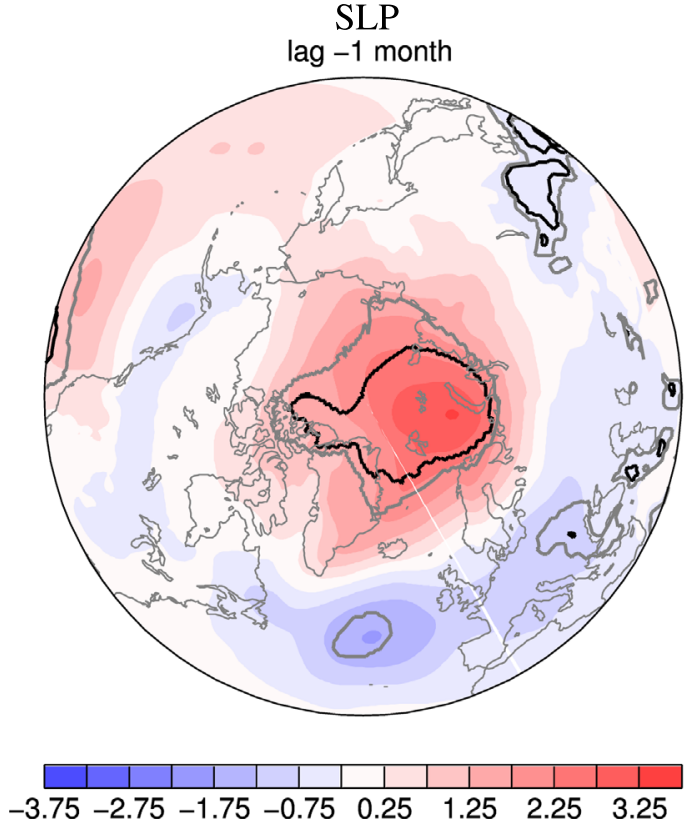

b

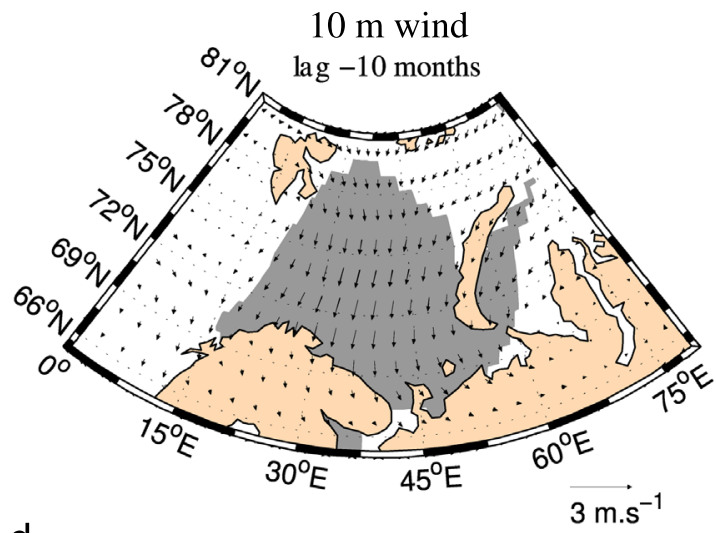

d

SAT

lag -1 month

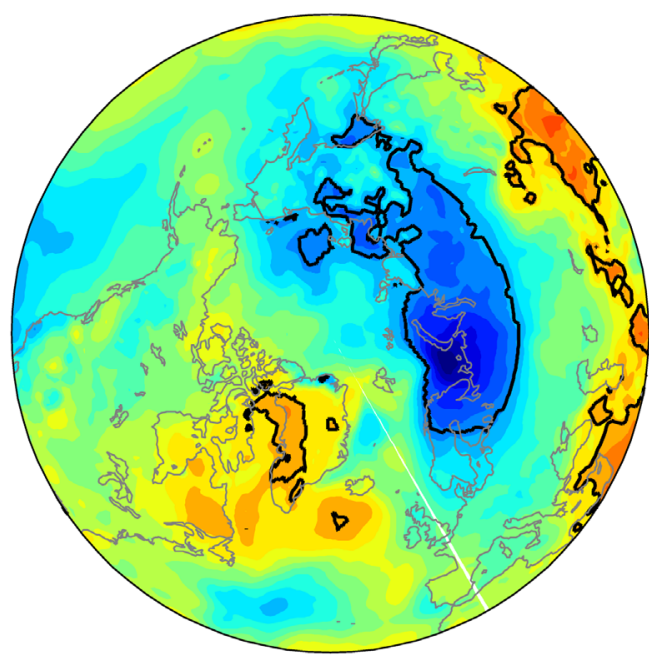

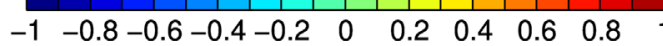

Fig. 14. same as Fig. 6 but for the eastern index.

wind in early winter (DJF) onto the eastern SIA index displays a easterly wind anomaly over the central Barents Sea and northeasterly wind anomalies in the southeastern Barents Sea (Fig 14a).
Consistently enhanced SIA in the eastern Barents Sea is associated with a positive SLP anomaly that is centered over the Kara Sea and extends over the eastern Barents Sea (Fig. 14c). This SLP pattern is a

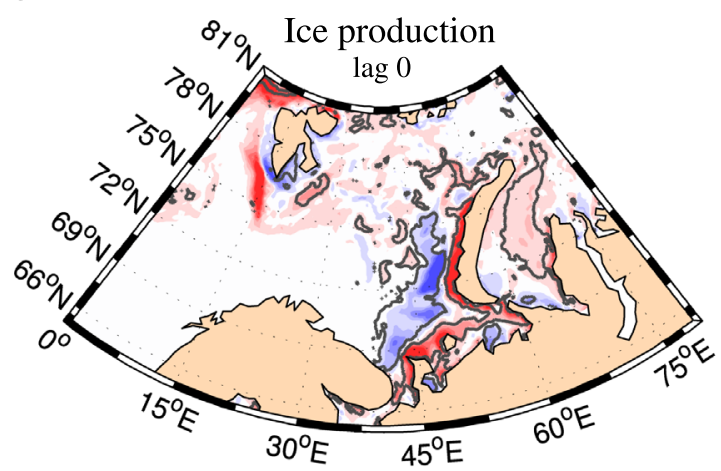

b

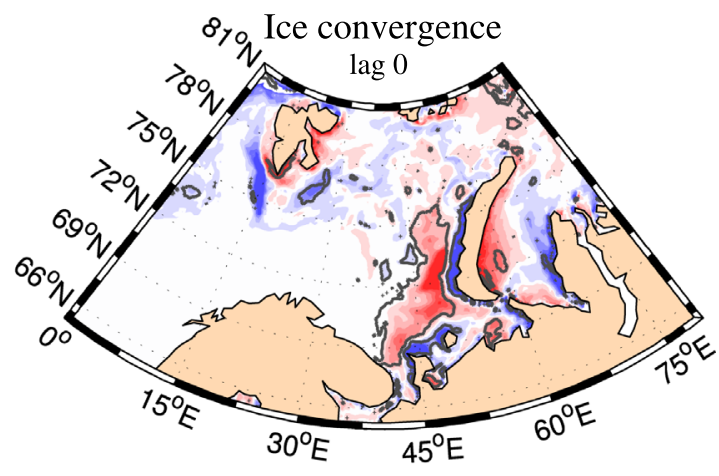

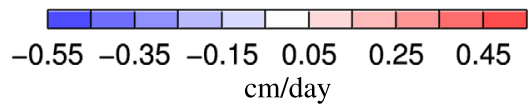

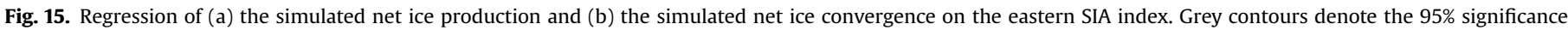
level. 
clearly distinct from the $\mathrm{AO}$ pattern, in agreement with the eastern SIA index and the AO index being uncorrelated. As for the northern SIA index, a second relative maximum in the correlation between the surface wind and the eastern SIA index is found in early spring, at lag -10 months. Similarly to the regression on the northern SIA index, the corresponding wind pattern reveals the predominance of meridional wind anomalies (Fig. 14b). However, the strongest anomalies are located in the northern Barents Sea for the northern SIA index (Fig. 6b), and in the southern Barents Sea for the eastern SIA index (Fig. 14b).

Concomitantly with the winter northeasterly wind anomalies, net ice production occurs along the western coast of Novaya Zemlya and in the southeastern Barents Sea (Fig. 15a), whereas net ice melt dominates off shore. The regression of the ice convergence displays a similar dipole pattern but with opposite sign (Fig. 15b), suggesting that the southwestward wind anomalies associated with positive phases of the eastern SIA index advect the ice offshore, and promote ice growth along Novaya Zemlya. This process would drive an increase in the SIA and sea ice extent.

In contrast to the northern SIA index, no clear link is found in the observations between the eastern SIA index and the AW temperature at BSO in any season. However, the eastern SIA index displays significant correlation with the temperature farther east at the Kola section, at all lags from lag 0 back to the previous summer and spring. Nevertheless, the correlations are weaker (less than -0.55) than those found with the northern SIA index (maximum correlation exceeds -0.7 ). The model results confirm that the eastern SIA index has no obvious direct link with the winter AW temperature variability at BSO. The simultaneous regression of the AW temperature onto the eastern SIA index displays a pattern that is limited to the eastern part of the Barents Sea (Fig. 16a). In the previous summer, the significantly correlated areas are located further west and resemble those associated with the northern SIA index; however, they do not extend into BSO (Fig. 16b). In the previous winter, the significantly correlated area reduces to a tiny domain, in contrast with the regression on the northern SIA index. Consistently, the heat transport through BSO does not correlate with the eastern SIA index at any lag.

\section{Discussion}

Using satellite observations and a coupled ocean-sea-ice model, two modes of variability of the winter sea ice margin have been identified in the Barents Sea over the period 1979-2004. The first mode (northern SIA index) describes the variability of the sea ice area in the northern Barents Sea, whereas the second mode (eastern SIA index) is associated with the variability in the southeastern Barents Sea. These two modes are not significantly correlated.

\subsection{Influence of the wind on the northern Barents Sea ice margin}

Separating the variability of the northern and southeastern sea ice margin based on two different, uncorrelated modes allows us to identify a strong, almost in phase influence of the wind on the sea ice distribution in the Barents Sea. While for the northern SIA mode the most influential component of the wind corresponds to northerly anomalies (explaining 70\% of the variance of the mode) because of their direct impact on the ice transport between Svalbard and Franz Josef Land, the eastern SIA mode exhibits the strongest relationship to northeasterly wind anomalies (explaining $70 \%$ of its variance). This difference in the forcing between the two modes may explain why, in contrast with our conclusions, earlier studies considering the variability of the entire Barents Sea SIA (Årthun et al., 2012; Schlichtholz, 2011) did not find such a large in-phase correlation between the wind and the Barents Sea ice cover. Instead, these authors found the strongest correlation with the wind when the wind led the SIA by 8-11 months. When we consider the SIA of the entire Barents Sea, the correlation with the SLP gradient between Svalbard and Novaya Zemlya, which can be viewed as an equivalent of the Off Ice Wind index used by Schlichtholz and Houssais (2011), is indeed strongest when the SLP gradient leads the ice by 10 months (Fig. $7 \mathrm{~b}$, red line). Switching to a measure of the SLP gradient that is more representative of the northerlies (between Svalbard and Severnaya Zemlya), the highest correlation between the sea ice and the wind is now found at lag -1 month (Fig. 7b, black line). In addition, while our analysis confirms Årthun et al. (2012) conclusion concerning the influence of the winter variations in the meridional wind on the circulation and temperature in the BSO and their possible impact on the SIA of the Barents Sea during the next winter, we do not find that this delayed impact dominates the response of the northern Barents Sea ice margin. In our model simulation, the temperature variability in the southwestern Barents Sea in winter explains only $35 \%$ of the variance of the northern SIA index in the following winter.

The SLP pattern that forces the variability of the northern SIA index closely resembles that identified by Pavlova et al. (2014) in relation to the variations in the April Barents Sea ice extent. Nakanowatari et al. (2014) and Sorteberg and Kvingedal (2006) also show the role of the meridional wind anomalies in forcing simultaneous variability of the northern ice edge in the Barents Sea in November-December and winter, respectively. However, Nakanowatari et al. (2014) emphasize a thermodynamic response of

b

a

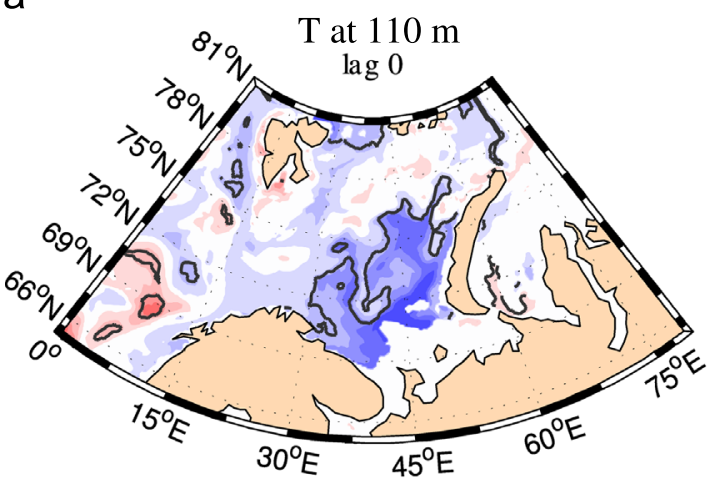

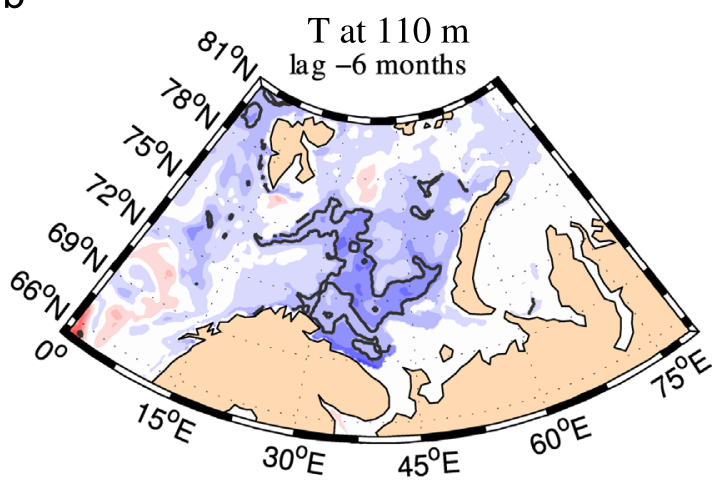

$$
\begin{array}{|c|c|c|c|c|c|c|}
\hline \mid & \mid & \mid & \mid & \mid & \mid \\
-0.55 & -0.35 & -0.15 & 0.05 & 0.25 & 0.45
\end{array}
$$

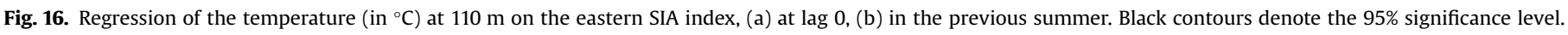


the sea ice to anomalous advection of air temperature, rather than a dynamic response of the ice via wind-driven drift anomalies, as suggested here. Although Sorteberg and Kvingedal (2006) have previously suggested the potential role of the Arctic ice export in the Barents Sea ice variability, they did not supply any evidence to support this mechanism.

Our winter SIA indices do not correlate with the AO. This is not surprising considering that they are rather responding to anomalies in the local meridional winds which can differ from AO-type wind anomalies. As established by Deser et al. (2000) and Ukita et al. (2007), the AO rather explains the covariability of the winter sea ice edge between the Atlantic and Pacific sectors of the Northern Hemisphere while, as observed by Schlichtholz (2011), it does not seem to drive the local variability of the SIA in the northern Barents Sea.

\subsection{Influence of the Atlantic water on the Barents Sea ice margin}

At lag -1 month, the meridional wind anomalies which force the northern mode of SIA variability over the central Barents Sea are accompanied by northeasterly wind anomalies in BSO (Fig. 6a) which would tend to reduce the inflow of AW through the BSO as was found in earlier studies (Ingvaldsen et al. 2004, Skagseth et al., 2008). This simultaneous impact of the wind on the ice and ocean may explain the significant correlation between the northern SIA index and the heat transport at BSO at lag -1 month. The correlation therefore would not imply direct causal links between the two variables; consistently, the time lag of two months found for the maximum of the correlation cannot be explained by the travelling time of the AW from BSO to the northern ice edge, which is at least 5-6 months.

The significant anticorrelation between the northern sea ice index and the AW temperature anomalies in the western Barents Sea (both in the observations and in our model simulation) in the previous winter strongly suggests some predictive skill of these anomalies with regard to the following winter sea ice cover. A similar skill of the winter subsurface temperature in the southwestern Barents Sea was found by Nakanowatari et al. (2014) in predicting Barents Sea ice concentration at the beginning of the following winter. However, the mechanisms leading to the formation of such anomalies were rather different. While Nakanowatari et al. suggest that the AW anomalies would be advected by the mean circulation from the North Atlantic Ocean, in our simulation they are rather formed locally by wind-driven heat transport convergence (with ocean-atmosphere heat fluxes playing a minor role in agreement with Smedsrud et al., 2010; and Sandø et al., 2010). The mechanism proposed here would explain why the lagged influence of the winter surface wind on the following winter sea ice cover identified here was also detected in some earlier studies (Schlichtholz, 2011; Årthun et al., 2012).

According to our results, the relationship between the AW temperature anomalies of the western Barents Sea and the northern sea ice index vanishes in summer, a result in contrast to Schlichtholz (2011) who found a high correlation between the summer temperature just west of BSO and the Barents Sea SIA in the following winter. The present study instead suggests that the statistical link between the summer temperature anomalies in BSO and the Barents Sea ice cover found by Schlichtholz (2011) would in fact not involve a direct causal effect. The link would rather be the manifestation of a common winter forcing (mainly meridional wind anomalies), generating SIC anomalies in the northern Barents Sea and widespread AW temperature anomalies at the same time. Part of the signal would be recirculated in the northern BSO and exported to the west of the opening, while the anomalies located in the southern BSO propagate with the AW inflow branch into the interior Barents Sea, reaching the ice edge in the following winter. The recirculation of the AW anomalies is supported by our model simulation, in which temperature anomalies are indeed detected in summer in the recirculation branch of the AW inflow (north of $73^{\circ} \mathrm{N}$ ), and a significant anticorrelation $(-0.62)$ is found between these anomalies and the winter SIA of the entire Barents Sea. It is also in agreement with the scenario proposed by Schlichtholz and Houssais (2011), in which AW temperature anomalies formed in the Barents Sea in late winter would be subsequently advected westward into BSO. It is interesting to note that, in our simulation, the southward expansion of the sea ice in the northern Barents Sea occurs concomitantly with an increase of the water outflow through BSO, which results in a decrease of the net heat inflow to the Barents Sea.

Lien et al. (2013) suggest that variations of the outflow branch in BSO are driven by sea level variations in the northern Barents Sea in response to changes in the wind stress circulation around this region. Taking the curl of the surface wind anomalies regressed on the northern SIA index (Fig. 6a) we find a significant clockwise anomaly over the northern Barents Sea, which would be consistent with an increase of the outflow through BSO as suggested by Lien et al. (2013).

Over the period 1979-2004, the influence of the winter AW temperature at BSO on the SIC of the following winter is mainly detected in the northeastern Barents Sea. This preferred region of influence was previously suggested by Nakanowatari et al. (2014) (see their Fig. 7a) and Schlichtholz (2013) when considering a period of observations extending beyond 2004. However, as shown in Fig. 4 (bottom panel), the SIA in the northeastern Barents Sea underwent a particularly abrupt decline after 2004 which was not preceded by any abrupt changes in the AW temperature at BSO (Fig. 4, top panel). Consistently, this sharp decrease of the Barents Sea SIA in 2005 is not reproduced by the predictive model of Onarheim et al. (2015) based on the observed oceanic heat transport through BSO, even if their model gives skillful prediction of the SIA over the full period of observations (see their Fig. 3). All these results suggest that additional mechanisms (including possible changes in the atmospheric circulation) must have been at play to produce this event.

Although the anomalies of the overall northern Barents Sea SIA do not persist until the following winter (Fig. 9), the northern SIA index displays significant covariance with the following winter SIC anomalies in the northeastern Barents Sea (Fig. 11c), the preferred site for interaction of the winter sea ice cover with reemerging AW temperature anomalies. Similar delayed response of the sea ice to ocean anomalies has been mentioned at the pan-arctic scale by Blanchard-Wrigglesworth et al. (2011) as SIC "reemergence". The latter was found to be the result of spring SST anomalies persisting through the summer and forcing the sea ice in the following fall. Here the proposed mechanism is somewhat different as it implies preservation of subsurface temperature anomalies generated in winter in the Atlantic layer in the western Barents Sea and their subsequent advection and reemergence through vertical mixing in fall and winter. This scenario of reemergence would be an alternative to the atmospheric state re-emergence mechanism, involving persistence of atmospheric anomaly patterns over several months, proposed by Bushuk et al. (2015). The similar wind anomalies at lag -1 month and -10 months in relation to the northern SIA index found in the present analysis might be interpreted as a manifestation of such a persistence. However, according to our analysis, the winter wind anomalies in the Barents Sea do not persist throughout a full year. The similarity of the wind anomalies at a 10 month time lag thus simply reflects the persistence, over that duration, of ocean heat anomalies, which are driven by the same wind anomalies as those influencing the sea ice. 
a

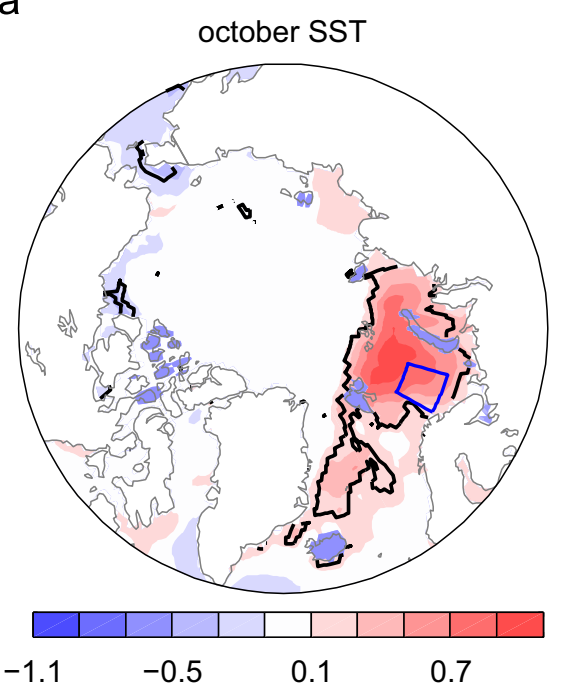

C
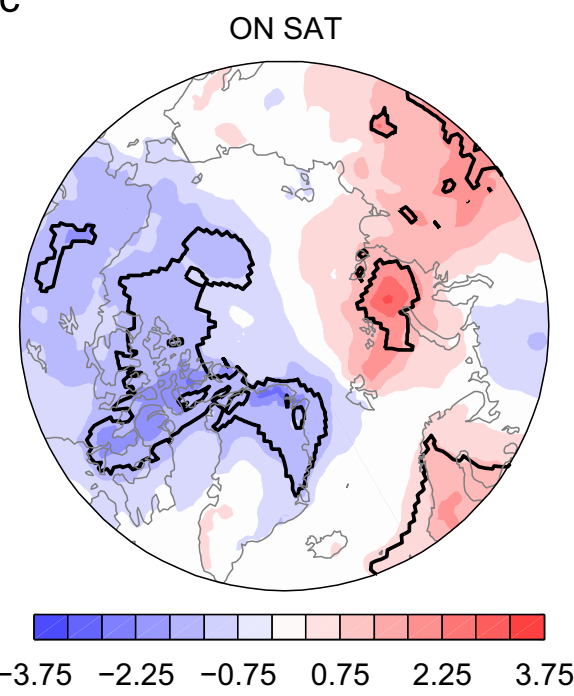

e

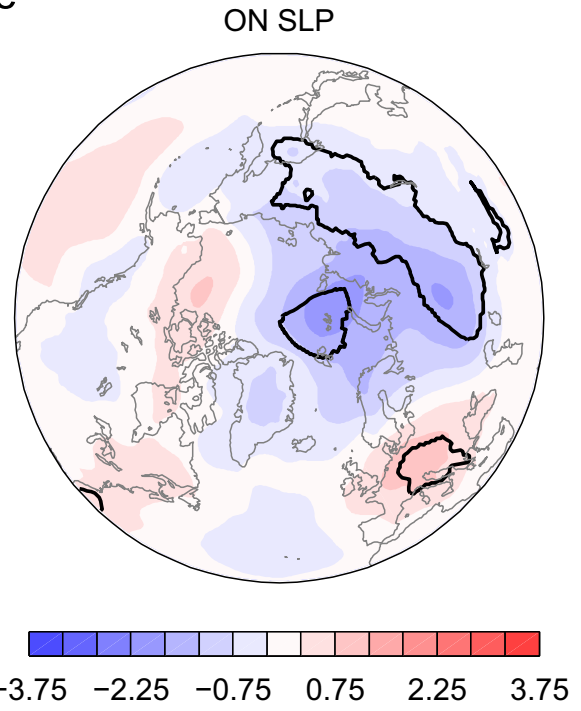

b
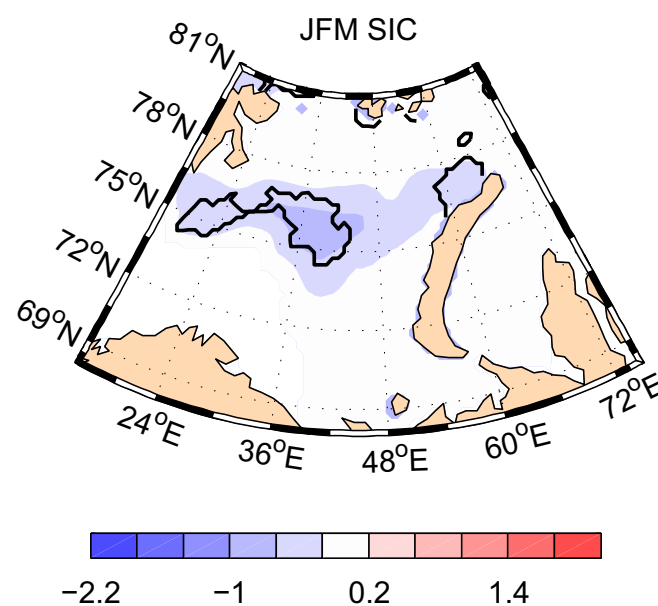

d

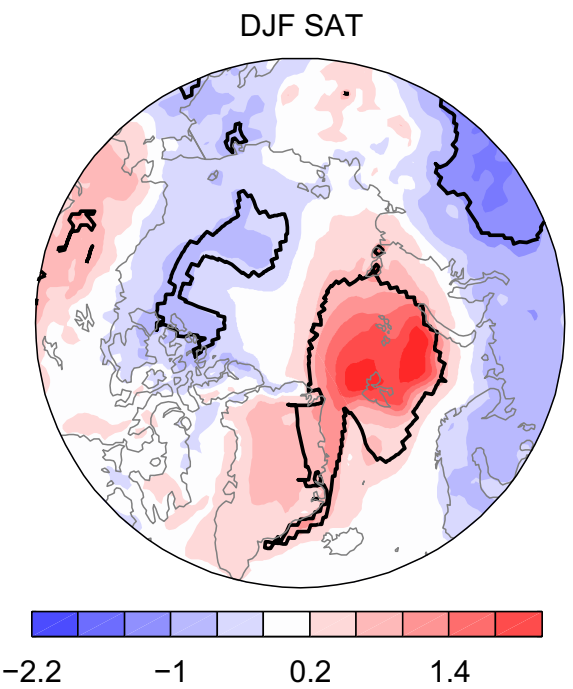

$\mathrm{f}$

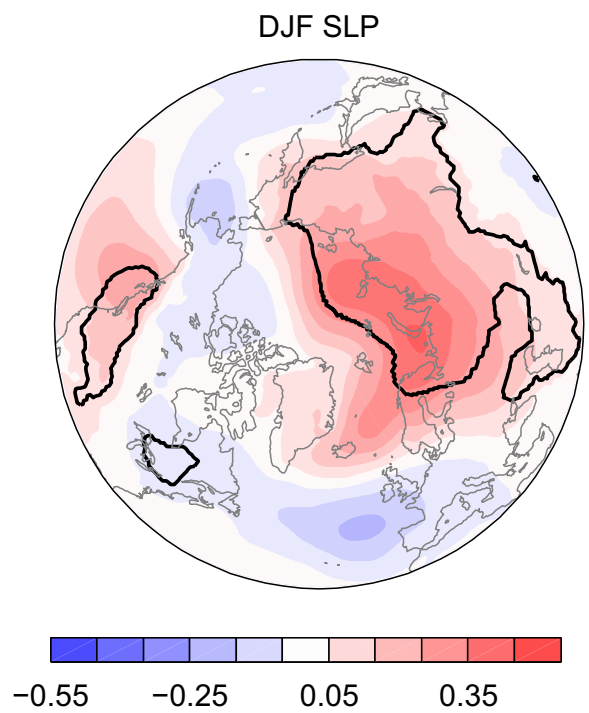

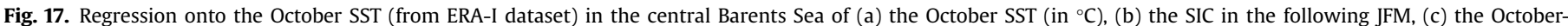

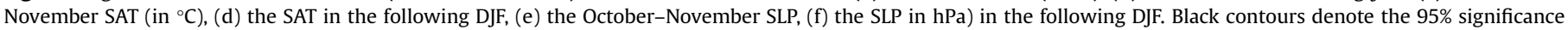
level. The SST index of the central Barents Sea is obtained by averaging data over the domain shown as a blue box in (a). 


\subsection{Ocean-atmosphere feedback}

The simulation results suggest that winter SIA anomalies in the northern Barents Sea are preceded by anomalies of SST in the previous fall and northerly winds in early winter. This statistical relationship would be consistent with a delayed response of the winter atmosphere to ocean surface conditions, and this mechanism has thus been investigated further. The October SST (obtained from the ERA-I reanalysis dataset) is used, as its regression onto the northern SIA index (not shown) is characterized by a pattern to the west of the Central Basin that is fairly similar to the mean seasonal fall pattern shown in Fig. 12b (except that the amplitude of the signal is larger). Comparing the regressions of the SST (Fig. 17a) and SIC (not shown), both taken in October, onto the SST averaged over the central Barents Sea (see blue box in Fig. 17a), a warming over the full Barents Sea region in October is found to be associated with a concomitant retreat of the sea ice in the Barents and Kara Seas. The ocean surface warming drives a surface atmosphere warming (Fig. 17c) and a decrease of the SLP (Fig. 17e) in October-November over the same region, the latter extending over Eurasia. While the SAT anomaly persists and intensifies over the following winter (Fig. 17d), the SLP anomaly switches sign (Fig. 17f). This evolution of the SLP from autumn to winter would be consistent with the atmospheric response to sea ice retreat described by Jaiser et al. (2012). These authors attributed the evolution of the SLP anomalies to a change from a baroclinic response of the atmosphere in autumn to a barotropic one in winter. In our analysis, the DJF SLP anomaly triggers wind anomalies with a dominant northward component which would reinforce the sea ice retreat in the northwestern Barents Sea (Fig. 17b).

The results presented here suggest that fall SST anomalies can indirectly influence the SIA in the northern Barents Sea by driving the same early winter surface wind changes that were shown to correlate with the northern SIA index. The influence of the AW temperature anomalies in fall on the northern ice edge would therefore occur through the combination of two processes: in addition to the re-emergence of subsurface temperature anomalies, which are expected to modify the sea ice growth mainly in the northeastern Barents Sea, we identify an ocean-to-atmosphere feedback, which promotes the formation of meridional wind and concomitant enhancement of sea ice drift anomalies.

A warming of the lower Arctic atmosphere in fall in response to enhanced Arctic-wide September sea ice retreat was previously noted in earlier studies (e.g. Hopsch et al., 2012), in some cases with a strong SAT (Screen et al., 2013) or SLP (Jaiser et al., 2012) signal over the Barents Sea (in the latter study, the SLP anomaly pattern was, however, less supportive of meridional wind anomalies). Our analysis provides another possible mechanism at the regional scale: early winter surface atmosphere anomalies could also be triggered by October SST anomalies found in the southern Barents Sea and linked to temperature anomalies formed in the Atlantic water inflow in the previous winter. Additionally, while other authors have highlighted a possible feedback of the SST onto the surface wind in the Barents Sea (Bengtsson et al., 2004; Schlichtholz, 2013), their studies mainly emphasized the influence of the SST anomalies on the zonal wind, rather than on the meridional wind as found here.

\subsection{Sea ice variability in the eastern Barents Sea}

In the southeastern Barents Sea, northeasterly wind anomalies transport the ice offshore and favor ice growth along the western coast of Novaya Zemlya and in the southeastern Barents Sea. Significant correlations of the eastern SIA index are also found with the northerly winds of the preceding early spring (lag -10 months) which would be consistent with some influence of the ocean. A delayed response of the eastern SIA index to earlier (spring) AW temperature variations at the Kola section is indeed found in the observations. However, upper ocean temperature anomalies could not be traced farther west in our model simulation, suggesting that the eastern index is less sensitive to the Atlantic water variability than the northern index. The AW pathways in the Barents Sea are indeed strongly constrained by the topography, which, in the southeastern Barents Sea, tends to divert the mean AW flow northward off the Novaya Zemlya shelf to form the Novaya Zemlya Branch. Cross-shelf exchanges may, of course, take place but these processes (which have yet to be identified in observations) are likely to be poorly represented in our non-eddy resolving simulation.

\subsection{Barents Sea ice variability after 2004}

The preceding results are based on an analysis of the period 1979-2004, when the average sea ice area in the Barents Sea was about $670000 \mathrm{~km}^{2}$. Since 2005 , the sea ice area has decreased rapidly, reaching a mean value of $400,000 \mathrm{~km}^{2}$ over the period 2005-2012. The robustness of our conclusions with regards to the mean sea ice conditions (or coverage) has been evaluated by considering the post-2004 period separately. Since the period is too short to permit any reliable statistical analysis, we built composites of the early winter SLP based on the northern and eastern SIA indices, without computing any statistical significance level. For the positive (negative) composites, we selected those years in which the indices are greater (lower) than $0.5(-0.5)$ standard deviation. Fig. 18a and b display the SLP difference between the positive and negative composites for the two SIA indices. The composite based on the northern SIA index shows a positive pole located over Svalbard, with a gradient in SLP between Svalbard and Severnaya Zemlya. As for the SLP regression onto the northern SIA index (Fig. 6c), this pattern would favor northward wind anomalies during periods associated with low values of the sea ice index. The composite based on the eastern SIA index shows an SLP pole over the Barents Sea, as in Fig. 14c, favoring northeasterly wind anomalies. In contrast to Fig. 14c, however, this pole extends farther over the Nordic Seas. The composite is dominated by the large SLP anomalies in 2010, which are associated with a very low AO index. These results suggest that the statistical relationship found between the wind and the SIA in the Barents Sea for the period 1979-2004 could have persisted afterwards. On the other hand, the link of the SIA with the ocean seems to have weakened after 2004. The regression of the SIC onto the preceding winter AW temperature at BSO during that period still suggests an influence of the latter (the time series in Fig. 18c indicates some consistent evolutions), but confined to the northeastern Barents Sea, while the central part of the northern ice margin is less affected (Fig. 18d). This result would be consistent with our finding that the Franz Josef Branch of the AW circulation is the most influential with regards to the northern sea ice margin. As the sea ice gradually retreated after 2004 , the relative influence of this branch on the SIC might have weakened. As a direct consequence of this change, the region of maximum variability of the SIC in the northern Barents Sea ice was shifted westward (Fig. 2d and f).

\section{Conclusions}

Our study has shown that a large part of the variability of the winter SIC in the Barents Sea can be explained by an in-phase response to the wind: northerly (northeasterly) wind anomalies drive enhanced sea ice extent in the northern (eastern) Barents Sea. A delayed response to the ocean variability is also observed: following late winter meridional wind anomalies and concomitant 
a

\section{SLP composites northern mode}

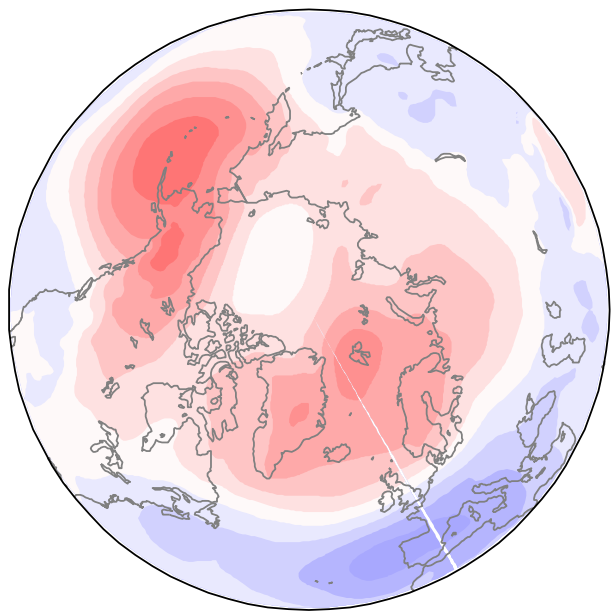

b

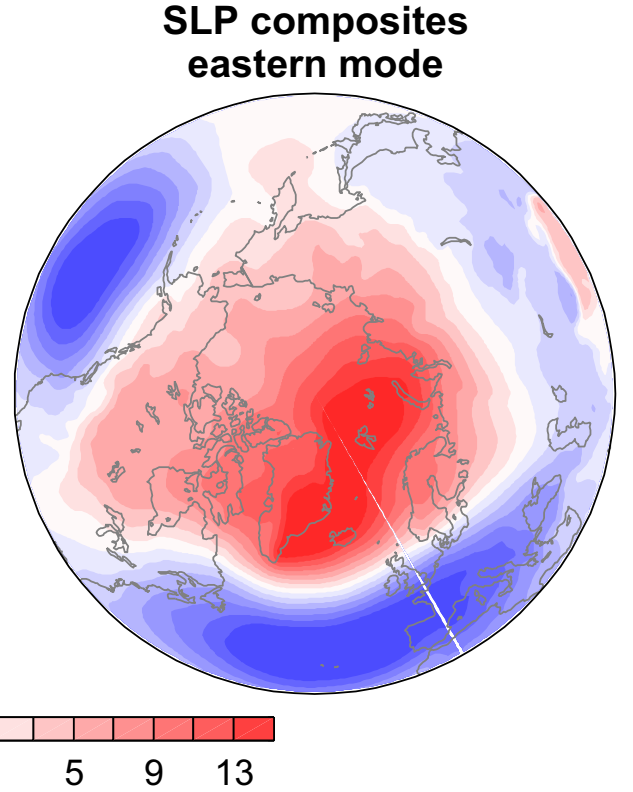

C

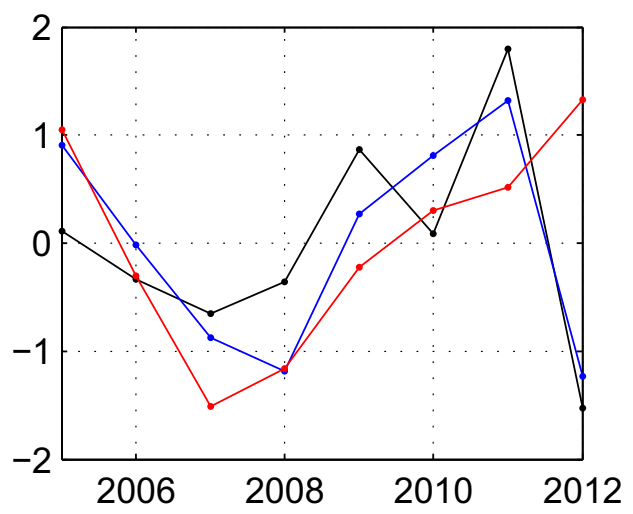

d

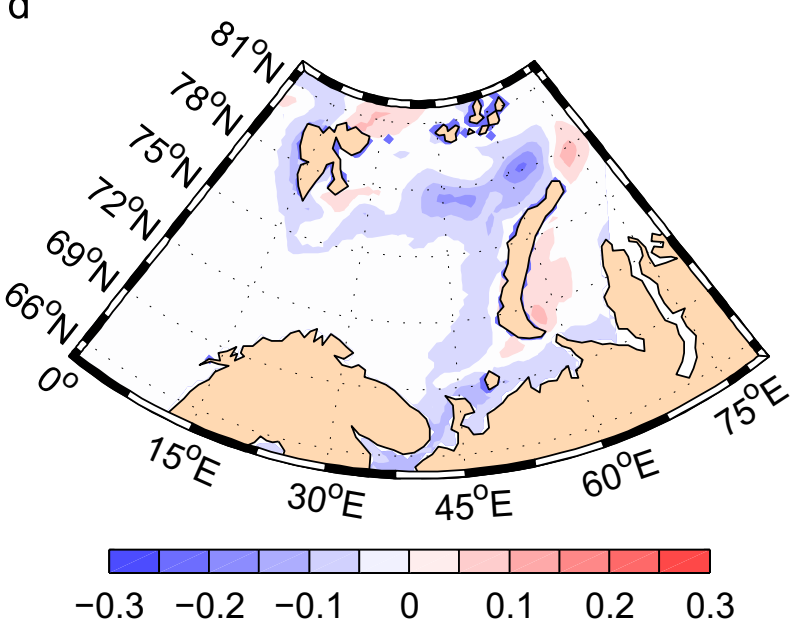

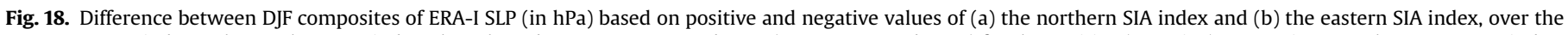

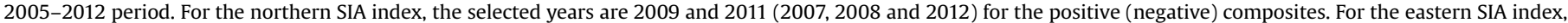

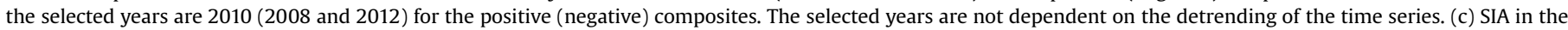

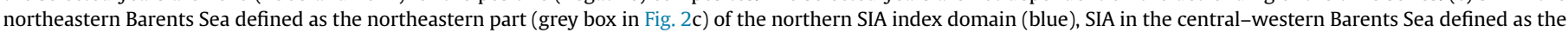

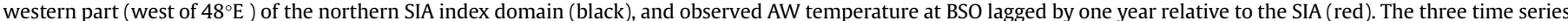

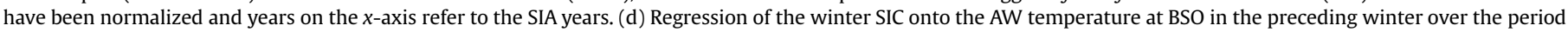
2005-2012. (For interpretation of the references to color in this figure legend, the reader is referred to the web version of this article.)

ocean heat content and circulation changes in the AW layer in the western Barents Sea, SIC anomalies may be reinforced in the following winter. While the fall-winter heat transport in the AW inflow branch through BSO correlates with the northern SIA index, the fact that the simultaneous correlation appears to be mainly due to the variations of the recirculating branch in northern BSO suggests a complex response of the AW circulation to the wind. This response obviously takes part in the build-up of subsurface temperature anomalies in the western Barents Sea which affect the sea ice cover in the northern Barents Sea with a 1-year time delay. Nevertheless, these anomalies do not show a straightforward relationship to the BSO transport and further analysis is required to better establish the link between the heat transport at BSO and the distribution and forcing of the heat pathways across the Barents Sea, especially in the Novaya Zemlya Branch and the Franz Josef Branch. This may help to better understand the delayed response of the sea ice to the heat transport through BSO suggested by the observations over the last fifteen years (Onarheim et al., 2015)

The separation into a northern and eastern mode of SIA variability in the Barents Sea helps to clarify the almost simultaneous response of the sea ice to the surface wind, and to highlight its predominance over the lagged response of the sea ice to the ocean. It should, however, be kept in mind that these relationships were established based on data from the earlier 1979-2004 period. The region which is most influenced by the AW temperature is the northeastern Barents Sea. This region underwent an abrupt sea ice decline after 2004 which can neither be linked to changes in the AW temperature, nor in the heat transport at BSO. This may suggest that the current "Atlantification" of the Barents Sea has changed the link between the Atlantic water inflow and the sea ice in the northern Barents Sea. In particular, as the sea ice edge 
retreats northward and warmer fall-winter conditions are established in the central Barents Sea, vertical ocean mixing may become less efficient, hindering the reemergence of the subsurface temperature anomalies and minimizing the delayed impact of the AW on the sea ice cover. If this were to be true, the 2005 event would then be a first manifestation of an altered (compared with the earlier period) relationship between the sea ice and the ocean in the Barents Sea.

The delayed influence of the AW on the sea ice, possibly reinforced by a feedback of the fall SST onto the atmosphere, provides a potential source of predictability for the winter atmosphere in the Barents Sea. This mechanism adds to other shorter term sources of predictability related to the summer Arctic sea ice minimum. However, while our analysis emphasizes the particular role of SST anomalies located in the central Barents Sea in this feedback, other analyses (Bengtsson et al., 2004; Schlichtholz, 2013) have highlighted surface heat flux anomalies confined to the northeastern Barents Sea. The atmospheric response to the surface conditions in the Barents Sea may therefore be very sensitive to the location of the SST anomalies, however, this spatial sensitivity is still to be ascertained.

\section{Acknowledgment}

The research leading to these results has received funding from the European Union 7th Framework Programme (FP7 2007-2013) under grant agreement n.308299, NACLIM Project. This work was performed using HPC resources from GENCI-[TGCC/CINES/IDRIS] (Grant 2001239). This work has also benefited from discussions during FAMOS meetings.

\section{References}

Alexander, M.A., Bhatt, U.S., Walsh, J.E., Timlin, M.S., Miller, J.S., Scott, J.D., 2004. The atmospheric response to realistic Arctic sea ice anomalies in an AGCM during winter. J. Clim. 17 (5), 890-905. http://dx.doi.org/10.1175/1520-0442(2004) $017<0890$ :TARTRA $>2.0$. CO 2 .

Årthun, M., Eldevik, T., Smedsrud, L.H., Skagseth, Ø., Ingvaldsen, R., 2012. Quantifying the influence of Atlantic heat on Barents Sea ice variability and retreat. J. Clim. 25, 4736-4743. http://dx.doi.org/10.1175/JCLI-D-11-00466.1.

Bengtsson, L., Semenov, V.A., Johannessen, O.M., 2004. The Early Twentieth-Century Warming in the Arctic-A Possible Mechanism. J. Clim. 17 (20), 4045-4057. http://dx.doi.org/10.1175/1520-0442(2004)017 < 4045:TETWIT > 2.0.CO;2.

Blanchard-Wrigglesworth, E., Armour, K.C., Bitz, C.M., DeWeaver, E., 2011. Persistence and inherent predictability of Arctic sea ice in a GCM ensemble and observations. J. Climate 24 (1), 231-250.

Bushuk, M., Giannakis, D., Majda, A.J., 2015. Arctic Sea Ice Reemergence: The Role of Large-Scale Oceanic and Atmospheric Variability. J. Climate 2015.

Bretherton, C.S., Widmann, M., Dymnikov, V.P., Wallace, J.M., Bladé, I., 1999. The Effective Number of Spatial Degrees of Freedom of a Time-Varying Field. J. Climate 12, 1990-2009. http://dx.doi.org/10.1175/1520-0442(1999)012 < 1990: TENOSD > 2.0.CO;2.

Cavalieri, D.J., Parkinson, C.L., 2012. Arctic sea ice variability and trends, 1979-2010. The Cryosphere 6, 881-889. http://dx.doi.org/10.5194/tc-6-881-2012.

Close, S., Houssias, M.N., abd Herbaut, C. Regional dependance in the timing of onset of rapid decline in Arctic sea ice concentration. J. Geophys. Res, in revision.

Comiso, J.C., 2006. Abrupt decline in the Arctic winter sea ice cover. Geophys. Res. Lett. 33, L18504. http://dx.doi.org/10.1029/2006GL027341.

Comiso, J., 2000, updated 2014: Bootstrap Sea Ice Concentrations from Nimbus-7 SMMR and DMSP SSM/I-SSMIS. Version 2. Boulder, Colorado USA: NASA DAAC at the National Snow and Ice Data Center.

Dee, D.P., et al., 2011. The ERA-interim reanalysis: Configuration and performance of the data assimilation system. Q. J. R. Meteorol. Soc. 137, 553-597. http://dx. doi.org/10.1002/qi.828.

Deser, C., Walsh, J., Timlin, M.S., 2000. Arctic sea ice variability in the context of recent atmospheric circulation trends. J. Climate 13, 617-633. http://dx.doi.org/ 10.1175/1520-0442(2000)013 < 0617:ASIVIT > 2.0.CO;2.

Deser, C., Tomas, R.A., Peng, S., 2007. The Transient Atmospheric Circulation Response to North Atlantic SST and Sea Ice Anomalies. J. Climate 20, 4751-4767. http://dx.doi.org/10.1175/JCLI4278.1.

Fichefet, T., Morales Maqueda, M.A., 1997. Sensitivity of a global sea ice model to the treatment of ice thermodynamics and dynamics. J. Geophys. Res. 102
$12,60912,646$

Francis, J.A., Chan, W., Leathers, D.J., Miller, J.R., Veron, D.E., 2009. Winter Northern Hemisphere weather patterns remember summer Arctic sea-ice extent. Geophys. Res. Lett. 36, L07503. http://dx.doi.org/10.1029/2009GL037274.

Gerber, F., Sedláček, J., Knutti, R., 2014. Influence of the western North Atlantic and the Barents Sea on European winter climate. Geophys. Res. Lett. 41, 561-567. http://dx.doi.org/10.1002/2013GL058778.

Ingvaldsen, R., Asplin, L., Loeng, H., 2004. The seasonal cycle in the Atlantic transport to the Barents Sea during the years 1997-2001. Cont. Shelf Res. 24, $1015-1032$

Jaiser, R., Dethloff, K., Handorf, D., Rinke, A., Cohen, J., 2012. Impact of sea ice cove changes on the Northern Hemisphere atmospheric winter circulation. Tellus 64A; p. 11595. http://dx.doi.org/10.3402/tellusa.v64i0.11595.

Kern, S., Kaleschke, L., Spreen, G., 2010. Climatology of the Nordic (Irminger, Greenland, Barents, Kara, White/Pechora) Seas ice cover based on $85 \mathrm{GHz}$ satellite microwave radiometry: 1992-2008. Tellus A 62A, 411-434. http://dx.doi. org/10.1111/j.1600-0870.2010.00457.x.

Kwok, R., 2009. Outflow of Arctic Ocean sea ice into the Greenland and Barents Seas: 1979-2007. J. Clim. 22 (9), 2438-2457. http://dx.doi.org/10.1175/ 2008JCLI2819.1.

Kwok, R., Cunningham, G.F., 2008. ICESat over Arctic sea ice: Estimation of snow depth and ice thickness. J. Geophys. Res. 113, C08010. http://dx.doi.org/10.1029/ 2008JC004753.

Large, W.G., Yeager, S.G, 2004.. Diurnal to decadal global forcing for ocean and seaice models: the data sets and flux climatologies. In: NCAR Technical Note.NCAR/ TN-460+STR.

Liptak, J., Strong, C., 2014. The Winter Atmospheric Response to Sea Ice Anomalies in the Barents Sea. J. Climate 27, 914-924. http://dx.doi.org/10.1175 JCLI-D-13-00186.1.

Lien, V., Vikebø, F.B., Skagseth, Ø., 2013. One mechanism contributing to co-variability of the Atlantic inflow branches to the Arctic. Nat. Commun. 4, 1488. http: //dx.doi.org/10.1038/ncomms2505.

Loeng, H., 1991. Features of the physical oceanographic conditions of the Barents Sea. Polar Res. 10 (1), 5-18.

Madec, G., 2008. NEMO ocean engine, Note du pôle de modélisation. Institut Pierre Simon Laplace (IPSL), France, No 27 ISSN No 1288-1619.

Nakanowatari, T., Sato, K., Inoue, J., 2014. Predictability of the Barents Sea Ice in early winter: remote effects of oceanic and atmospheric thermal conditions from the North Atlantic. J. Climate 27, 8884-8901. http://dx.doi.org/10.1175/ JCLI-D-14-00125.1.

Onarheim, I.H., Eldevik, T., Årthun, M., Ingvaldsen, R.B., Smedsrud, L.H., 2015. Skillful prediction of Barents Sea ice cover. Geophys. Res. Lett. 42, 5364-5371. http://dx.doi.org/10.1002/2015GL064359.

Ozhigin, V.K., Trofimov, A.G., Ivshin, V.A., 2000. The Eastern Basin Water and currents in the Barents Sea. ICES 14, 1-19.

Pavlova, O., Pavlov, V., Gerland, S., 2014. The impact of winds and sea surface temperatures on the Barents Sea ice extent, a statistical approach. J. Mar. Sys. 130, 248-255. http://dx.doi.org/10.1016/j.jmarsys.2013.02.011.

Petoukhov, V., Semenov, V.A., 2010. A link between reduced Barents-Kara sea ice and cold winter extremes over northern continents. J. Geophys. Res. 115, D21111. http://dx.doi.org/10.1029/2009jd013568.

Rigor, I.G., Wallace, J.M., Colony, R.L., 2002. Response of sea-ice to the Arctic Oscillation. J. Clim. 15, 2648-2663. http://dx.doi.org/10.1175/1520-0442(2002) $015<2648$ :ROSITT $>2.0$. CO 2 .

Rigor, I.G., Colony, R.L., Martin, S., 2000. Variations in surface air temperature observations in the Arctic, 1979-97. J. Climate 13, 896-914. http://dx.doi.org/ 10.1175/1520-0442(2000)013< 0896:VISATO > 2.0.CO 2

Rodionov, S.N., Overland, J.E., 2005. Application of a sequential regime shift detection method to the Bering Sea ecosystem. ICES J. Mar. Sci. 62, 328-332.

Rossow, W.B., Schiffer, R.A., 1999. Advances in Understanding Clouds from ISCCP. Bull. Am. Meteor. Soc. 80, 2261-2288. http://dx.doi.org/10.1175/1520-0477 (1999) $080<2261$ :AIUCFI > 2.0.CO;2.

Sandø, A.B., Gao, Y., Langehaug, H.R., 2014. Poleward ocean heat transports, sea ice processes, and Arctic sea ice variability in NorESM1-M simulations. J. Geophys. Res. Oceans 119, 2095-2108. http://dx.doi.org/10.1002/2013JC009435.

Sandø, A.B., Nilsen, J.E.Ø., Gao, Y., Lohmann, K., 2010. Importance of heat transport and local air-sea heat fluxes for Barents Sea climate variability. J. Geophys. Res. 115, C07013. http://dx.doi.org/10.1029/2009JC005884.

Schlichtholz, P., 2013. Observational evidence for oceanic forcing of atmospheric variability in the Nordic Seas Area. J. Climate 26, 2957-2975. http://dx.doi.org/ 10.1175/JCLI-D-11-00594.1.

Schlichtholz, P., 2011. Influence of oceanic heat variability on sea ice anomalies in the Nordic Seas. Geophys. Res. Lett. 38, L05705. http://dx.doi.org/10.1029/ 2010GL045894.

Schlichtholz, P., Houssais, M.-N., 2011. Forcing of oceanic heat anomalies by air-sea interactions in the Nordic Seas area. J. Geophys. Res. 116, C01006. http://dx.doi. org/10.1029/2009JC005944.

Screen, J.A., Simmonds, I., Deser, C., Tomas, R., 2013. The atmospheric response to three decades of observed Arctic Sea ice loss. J. Climate 26, 1230-1248. http: //dx.doi.org/10.1175/JCLI-d-12-00063.1.

Skagseth, Ø., Drinkwater, K.F., Terrile, E., 2011. Wind- and buoyancy-induced transport of the Norwegian Coastal Current in the Barents Sea. J. Geophys. Res. 116, C08007. http://dx.doi.org/10.1029/2011JC006996.

Skagseth, Ø., Furevik, T., Ingvaldsen, R., Loeng, H., Mork, K.A., Orvik, K.A., Ozhigin, V., 2008. Volume and heat transports to the Arctic Ocean via the Norwegian and Barents Seas, in Arctic Subarctic Ocean Fluxes. In: Dickson, R., Meincke, J., 
Rhines, M. (Eds.), Defining the Role of the Northern Seas in Climate. Springer, New York, pp. 45-64.

Skagseth, Ø., 2008. Recirculation of Atlantic Water in the western Barents Sea. Geophys. Res. Lett. 35, L11606. http://dx.doi.org/10.1029/2008GL033785.

Smedsrud, L.H., Ingvaldsen, R., Nilsen, J.E.Ø., Skagseth, Ø., 2010. Heat in the Barents Sea: transport, storage, and surface fluxes. Ocean Sci. 6, 219-234. http://dx.doi. org/10.5194/os-6-219-2010.

Sorteberg, A., Kvingedal, B., 2006. Atmospheric Forcing on the Barents Sea Winter Ice Extent. J. Climate 19, 4772-4784. http://dx.doi.org/10.1175/JCLI3885.1.

Steele, M., Morley, R., Ermold, W., 2001. PHC: A global ocean hydrography with a high quality Arctic Ocean. J. Climate 14, 2079-2087. http://dx.doi.org/10.1175/ 1520-0442(2001)014<2079:PAGOHW > 2.0.CO;2.

Strong, C., Magnusdottir, G., Stern, H., 2009. Observed Feedback between Winter Sea Ice and the North Atlantic Oscillation. J. Climate 22, 6021-6032. http://dx. doi.org/10.1175/2009JCLI3100.1.

Stroeve J.C., Serreze M.C., Holland M.M., Kay J.E., Maslanik J. and Barrett A.P., The
Arctic's rapidly shrinking sea ice cover: a research synthesis, Clim. Chang. 110. http://dx.doi.org/10.1007/s10584-011-0101-1.

Ukita, J., Honda, M., Nakamura, H., Tachibana, Y., Cavalieri, D.J., Parkinson, C.L., Koide, H., Yamamoto, K., 2007. Northern Hemisphere sea ice variability: lag structure and its implications. Tellus A 59, 261-271. http://dx.doi.org/10.1111/ j.1600-0870.2006.00223.x.

Yang, S., Christensen, J.H., 2012. Arctic sea ice reduction and European cold winters in CMIP5 climate change experiments. Geophys. Res. Lett. 39, L20707. http://dx. doi.org/10.1029/2012GL053338.

Yang, X.-Y., Yuan, X., 2014. The Early Winter Sea Ice Variability under the Recent Arctic Climate Shift. J. Climate 27, 5092-5110. http://dx.doi.org/10.1175/ JCLI-D-13-00536.1.

Zhang, J., Lindsay, R., Schweiger, A., Steele, M., 2013. The impact of an intense summer cyclone on 2012 Arctic sea ice retreat. Geophys. Res. Lett. 40, 720-726. http://dx.doi.org/10.1002/grl.50190. 